\title{
The annual surface energy budget of a high-arctic permafrost site on Svalbard, Norway
}

\author{
S. Westermann ${ }^{1}$, J. Lüers ${ }^{2}$, M. Langer ${ }^{1}$, K. Piel ${ }^{1}$, and J. Boike ${ }^{1}$ \\ ${ }^{1}$ Alfred-Wegener-Institute for Polar and Marine Research, Telegrafenberg A43, 14473 Potsdam, Germany \\ ${ }^{2}$ Department of Micrometeorology, University of Bayreuth, 95440 Bayreuth, Germany
}

Received: 11 August 2009 - Published in The Cryosphere Discuss.: 27 August 2009

Revised: 6 December 2009 - Accepted: 13 December 2009 - Published: 18 December 2009

\begin{abstract}
Independent measurements of radiation, sensible and latent heat fluxes and the ground heat flux are used to describe the annual cycle of the surface energy budget at a high-arctic permafrost site on Svalbard. During summer, the net short-wave radiation is the dominant energy source, while well developed turbulent processes and the heat flux in the ground lead to a cooling of the surface. About $15 \%$ of the net radiation is consumed by the seasonal thawing of the active layer in July and August. The Bowen ratio is found to vary between 0.25 and 2 , depending on water content of the uppermost soil layer. During the polar night in winter, the net longwave radiation is the dominant energy loss channel for the surface, which is mainly compensated by the sensible heat flux and, to a lesser extent, by the ground heat flux, which originates from the refreezing of the active layer. The average annual sensible heat flux of $-6.9 \mathrm{Wm}^{-2}$ is composed of strong positive fluxes in July and August, while negative fluxes dominate during the rest of the year. With $6.8 \mathrm{Wm}^{-2}$, the latent heat flux more or less compensates the sensible heat flux in the annual average. Strong evaporation occurs during the snow melt period and particularly during the snowfree period in summer and fall. When the ground is covered by snow, latent heat fluxes through sublimation of snow are recorded, but are insignificant for the average surface energy budget. The near-surface atmospheric stratification is found to be predominantly unstable to neutral, when the ground is snow-free, and stable to neutral for snow-covered ground. Due to long-lasting near-surface inversions in winter, an average temperature difference of approximately $3 \mathrm{~K}$ exists between the air temperature at $10 \mathrm{~m}$ height and the surface temperature of the snow.
\end{abstract}

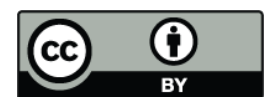

Correspondence to: S. Westermann (sebastian.westermann@awi.de)
As such comprehensive data sets are sparse for the Arctic, they are of great value to improve process understanding and support modeling efforts on the present-day and future arctic climate and permafrost conditions.

\section{Introduction}

In permafrost regions, the partitioning of energy at the surface is a crucial process, which strongly influences the heat flux into the ground and thus ultimately the thermal conditions of the permafrost. This surface energy budget depends on a number of factors, such as the available radiation, synoptic weather conditions, surface characteristics and soil moisture. Ground-based measurements, satellite data and results of climate modeling have revealed an ongoing warming trend in the Arctic (e.g. Serreze et al., 2000; Hansen et al., 2001; Comiso and Parkinson, 2004; Comiso et al., 2008; Overland et al., 2008). On Svalbard, a significant warming of air temperatures since 1960 has been detected, which is mainly attributed to changes in circulation patterns (Hanssen-Bauer and Førland, 1998). This is also reflected in permafrost temperatures, which display a significant warming (Isaksen et al., 2001, 2007). Climate models predict an accelerated future warming trend, with the largest warming occurring during winter (Førland and Hanssen-Bauer, 2003).

Such large-scale changes will be modulated by the locally determined conditions of the surface energy budget, which may result in an amplification as well as in a damping of the large-scale signal on the local scale. Moreover, a modification of the surface energy budget over large areas within the Arctic, e.g. triggered by a change in the vegetation, can even induce a feedback on the climate system (Chapin et al., 2005). Hereby, land-atmosphere exchange processes, i.e.

Published by Copernicus Publications on behalf of the European Geosciences Union. 
turbulent fluxes of sensible and latent heat, play a dominant role, as they vary considerably depending on the surface cover (Chapin et al., 2000; Eugster et al., 2000).

The redistribution of energy at the surface is one of the driving forces for the global climate system. The basic contributions of the surface energy budget are the short- and long-wave radiation, the sensible and latent heat fluxes and the ground heat flux. The adequate representation of this surface forcing is one of the challenges in atmospheric circulation models, on which predictions on climate change are based. The models make use of mostly semi-empirical parameterizations of the different fluxes of the surface energy budget, which have usually been developed and validated for non-arctic regions (e.g. Viterbo and Beljaars, 1995). In the Arctic, the perennial snow cover and the annual snowmelt, which greatly modify the surface processes for a large part of the year, constitute additional challenges for modeling which have not yet been fully resolved (Douville et al., 1995; Slater et al., 1998). Another unresolved problem is the parameterization of the sensible and latent heat fluxes during stable atmospheric stratification conditions which frequently occur in the arctic winter (Zilitinkevich et al., 2002; Lüers and Bareiss, 2009a). The same problems occur in processorientated permafrost models (Hoelzle et al., 2001), which in principle use the same parameterizations of the surface energy budget to evaluate the ground heat flux and the thermal conditions of the subjacent permafrost (Hinzman et al., 1995; Ling and Zhang, 2004).

Direct measurements of the surface energy budget in arctic regions are therefore indispensable to evaluate the performance of the employed flux parameterizations and surface parameter sets, especially if the study can provide the entire annual cycle and thus a complete picture including snow-associated processes. Great efforts have been initiated to study the annual cycle of the surface energy budget over arctic sea ice (Persson et al., 2002; Uttal et al., 2002), while comprehensive long-term studies are still missing for arctic land areas.

Under arctic conditions, particularly the quantification of sensible and latent heat fluxes still remains a challenging task (Lynch et al., 1999). The eddy covariance method has proven to be most suitable to directly measure sensible and latent heat fluxes (Foken, 2008b) and its potential has been demonstrated in a number of studies in the Arctic (McFadden et al., 1998; Oechel et al., 1998; Vourlitis and Oechel, 1999; McFadden et al., 2003). However, due to the difficult logistics and the extreme environmental conditions, few long-term eddy covariance studies of land-atmosphere exchange processes exist in arctic regions (Grachev et al., 2007; Stöckli et al., 2008). On Svalbard, they have been limited to short study periods during spring (Georgiadis et al., 2000), during the snow melt period (Harding and Lloyd, 1998; Lüers and Bareiss, 2009a) and during summer (Lloyd et al., 2001). In addition, the surface energy budget during the snow melt period has been investigated with techniques other than eddy covariance (Takeuchi et al., 1995; Nakabayashi et al., 1996; Boike et al., 2003a,b).

This study presents eddy covariance measurements of the sensible and latent heat flux at a high-arctic permafrost site on Svalbard, which were conducted over a full seasonal cycle from March 2008 to March 2009. The eddy covariance measurements are complemented by measurements of the radiative parts of the energy budget and the ground heat flux, so that a complete set of independent measurements of all contributions of the surface energy budget is accessible at a temporal resolution of one hour for an entire year. In this study, we focus on the annual and diurnal cycles of the surface energy budget. This not only allows to identify the driving parameters of the coupled permafrost-snow-atmosphere system, but also provides a basis for further investigations and modeling efforts, e.g. on the impact of small-scale variations of the surface cover on the local energy budget and the thermal conditions of the subjacent permafrost.

While the current study extends the sparse data set on the surface energy budget in the Arctic, we hope to encourage similar studies at other circumarctic locations, which would greatly improve the understanding of the climate of highlatitude ecosystems and its susceptibility to climate change.

\section{Study site}

\subsection{Climatological conditions}

Ny-Ålesund is situated at the Kongsfjorden in NW Svalbard (Fig. 1a). It has long been in the focus of a wide range of measurement campaigns and long-term monitoring programs, which have created an outstanding data basis, particularly with respect to climatological and atmospheric variables (e.g. Yamanouchi and Ørbaek, 1995; Beine et al., 2001; Winther et al., 2002). The area is strongly influenced by the North Atlantic Current, leading to a maritime climate with cool summer and comparatively mild winter temperatures. The average air temperature is around $+5^{\circ} \mathrm{C}$ in July and $-13{ }^{\circ} \mathrm{C}$ in January, with an annual precipitation of around $400 \mathrm{~mm}$ (Førland et al., 1997). The short-wave radiation budget naturally follows the rhythm of polar night and day, but is strongly modulated by albedo changes due to the seasonality of the snow cover. The snow-free period can vary from 50 to 150 days, but the typical duration is around three months (Winther et al., 2002).

During summer, the west coast of Svalbard is predominantly influenced by moist atlantic air masses, which leads to a high percentage of cloudy days. In winter, it is under the influence of both moist atlantic and dry polar air masses, which are typically associated with comparatively warm air temperatures with overcast skies and cold air temperatures with clear skies, respectively (e.g. Førland et al., 1997). As a result of the exchange of the air masses during winter, the incoming long-wave radiation is found to vary over a wide 


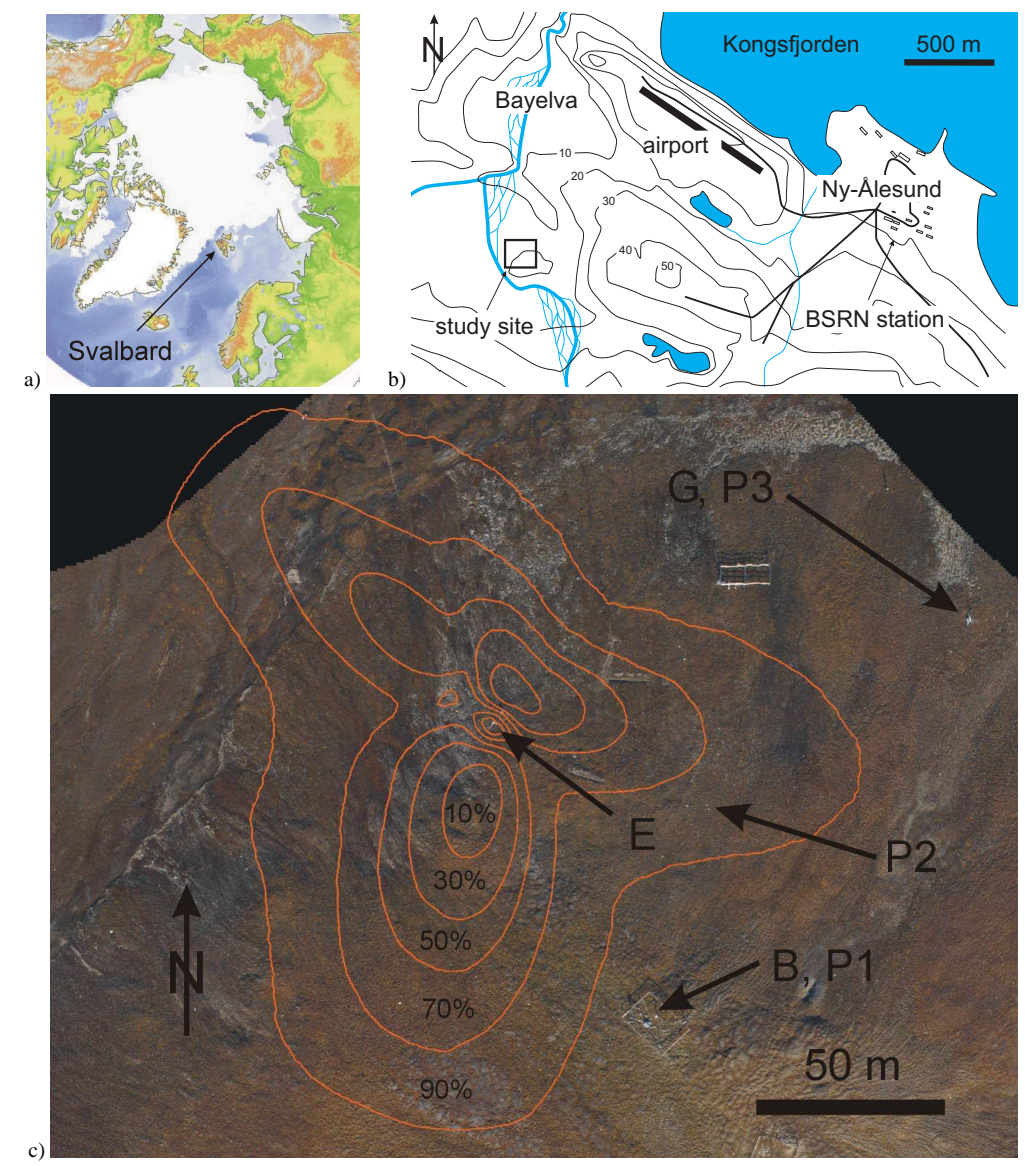

Fig. 1. (a) Map of the Arctic. (b) Location of the study site and the BSRN site; thick black lines: roads; contour lines in meters above sea level. (c) Orthorectified aerial photo with all installations (E: eddy covariance system; B: Bayelva climate station; G: gradient tower; P1, P2, P3: temperature profile measurements). The average footprint of the eddy covariance system from 1 July to 30 September 2008 is shown, with the percentages of the total flux originating within the respective contours.

range, while its range is much smaller during summer (Yamanouchi and Ørbaek, 1995).

Compared to the reference period 1961 to 1990 , about $10 \%$ more precipitation was recorded during the study period, while the observed air temperature was on average $1.5 \mathrm{~K}$ warmer (eklima, 2009). Therefore, the study period integrates well in the warming trend found for the last decade (Førland and Hanssen-Bauer, 2003), and does not represent exceptionally warm conditions, which have been recorded previously (e.g. Isaksen et al., 2007). With less than half of the precipitation of the long-term average, the first half of the study period from March to August 2008 was drier, while considerably more precipitation was measured from September 2008 to March 2009. With almost $100 \mathrm{~mm}$ of precipitation each, the months of September and December 2008 stood out with more than twice of the long-term average. However, similar precipitation rates have been observed at a number of occasions in fall and early winter since 2000 (eklima, 2009), so that the second half of the study period must be considered "wet conditions" rather than an extreme excep- tion. The Kongsfjorden, located $2 \mathrm{~km} \mathrm{NE}$ of the study area (Fig. 1b), was free or almost free of sea ice during the entire study period, which has been the case since 2006 (Gerland and Renner, 2007; Cottier et al., 2007, own observations).

\subsection{Site description}

The measurements were performed in the Bayelva catchment on the NW slope of Leirhaugen hill at $78^{\circ} 55^{\prime} \mathrm{N}, 11^{\circ} 50^{\prime} \mathrm{E}$ (Fig. 1b), located approximately $2 \mathrm{~km} \mathrm{SW}$ of the village of Ny-Ålesund. The observation site is situated in hilly tundra at the foot of two major glaciers at elevations of $15 \mathrm{~m}$ to $25 \mathrm{~m}$ above sea level and is characterized by sparse vegetation alternating with exposed soil and rock fields. On the top of Leirhaugen hill, the surface is covered with mud boils, a form of non-sorted circles. The soil at the study site features a high mineral content, while the organic content is low, with volumetric fractions below $10 \%$. The soil texture ranges from clay to silty loam (Boike et al., 2008). The Bayelva climate and soil monitoring station has provided a long-term 
record of climatological parameters and permafrost temperatures since 1998. At present, the permafrost at Leirhaugen hill is relatively warm, with a mean annual temperature around $-2{ }^{\circ} \mathrm{C}$ at $1.5 \mathrm{~m}$ depth. The maximum active layer depth in 2008 was on the order of $1.5 \mathrm{~m}$. Since the installation of the station, the average soil temperatures have increased significantly at the observation site (compare to Roth and Boike, 2001). The eddy covariance system is located at a slightly inclined slope $\left(<5^{\circ}\right)$. The flow paths in the main wind directions are unobstructed by man-made artificial structures, so that we can assume an undisturbed footprint area. An aerial picture with all installations is shown in Fig. 1c.

\section{Measurements}

\subsection{Definitions and constants}

$S_{\text {in }}$ : incoming short-wave radiation

$S_{\text {out }}$ : outgoing short-wave radiation

$\Delta S$ : net short-wave radiation

$L_{\text {in }}$ : incoming long-wave radiation

$L_{\text {out }}$ : outgoing long-wave radiation

$\Delta L:$ net long-wave radiation

$Q_{h}$ : sensible heat flux

$Q_{e}$ : latent heat flux

$Q_{g}$ : ground or snow heat flux

$Q_{\text {melt }}$ : energy flux consumed by melt of snow

$C$ : residual of the energy balance

$\Delta S+\Delta L+Q_{h}+Q_{e}+Q_{g}+Q_{\text {melt }}+C=0$

$u_{*}$ : friction velocity

$z_{0}$ : aerodynamic roughness length

$\xi=\mathrm{z} / \mathrm{L}$ : stability parameter (z: measurement height, L:

Obukhov length)

$T_{\text {air: }}$ air temperature

$T_{\text {surf }}$ : surface temperature

$\epsilon$ : Kirchhoff emissivity

$\sigma:$ Stefan-Boltzmann constant

$c_{p}$ : specific heat capacity of air at constant pressure

$\rho_{\text {air }}:$ density of air

$d_{h}$ : thermal diffusivity

$K_{h}$ : thermal conductivity

$c_{h}$ : volumetric heat capacity

$c_{h, \text { water }}=4.2 \mathrm{MJm}^{-3} \mathrm{~K}^{-1}$

$c_{h, \text { ice }}=1.9 \mathrm{MJm}^{-3} \mathrm{~K}^{-1}$

$c_{h, \text { mineral }}=2.0 \mathrm{MJ} \mathrm{m}^{-3} \mathrm{~K}^{-1}$

$c_{h, \text { organic }} \approx c_{h, \text { mineral }}$

$c_{h, \text { air }} \approx 0.001 \mathrm{MJm}^{-3} \mathrm{~K}^{-1}$

$\rho_{\text {ice }}=0.91 \mathrm{gcm}^{-3}:$ density of ice

$L_{\mathrm{sl}}=0.33 \mathrm{MJkg}^{-1}:$ specific latent heat of fusion of water

$L_{\mathrm{lg}}=2.5 \mathrm{MJkg}^{-1}$ : specific latent heat of vaporization of water
The surface is defined as the interface between the atmosphere and the soil or snow, respectively. We use the convention that fluxes, which transport energy away from the surface, are denoted positive and fluxes, which transport energy towards the surface, are denoted negative.

\subsection{Radiation}

The Bayelva climate station is located about $100 \mathrm{~m}$ from the eddy covariance site (Fig. 1c), where measurements of $S_{\text {in }}$ with a Skye Pyranometer SP1110 and $L_{\text {out }}$ with a Kipp \& Zonen CG1 long-wave radiation sensor are performed. $S_{\text {out }}$ and $L_{\text {in }}$ are not measured at the Bayelva station (see below). Under the extreme conditions of the Arctic, reliable radiation measurements are a challenging task. Since it is not possible to maintain the sensors at the Bayelva station regularly, a reduced accuracy and frequent data gaps must be accepted. However, a maintained station of the Baseline Surface Radiation Network (BSRN) is located in the village of Ny-Ålesund, about $2 \mathrm{~km}$ from the study site (Fig. 1b), where incoming and outgoing short- and longwave radiation are measured according to WMO accuracy standards (Ohmura et al., 1998). The BSRN data set can not be entirely assigned to the study site due to differences in the surface cover and the timing of the snow melt between both sites. However, the incoming long-wave radiation $L_{\text {in }}$ is used in this study, since it is mainly determined by the cloud cover and the atmospheric temperature and water vapor profile, which do not vary considerably between the two sites. Furthermore, the BSRN data are used as a reference to assess the quality of and, if necessary, to fill gaps in the Bayelva radiation data. In addition, the average surface albedo is inferred from measurements at the BSRN site to calculate $S_{\text {out }}$, except for the snow melt period. When the ground is covered by snow, systematic differences in the albedo of the undisturbed snow surfaces at the study and the BSRN site are not to be expected. When the ground is snow-free, the albedo at the two sites may be slightly different, though. In August 2008, the surface albedo was estimated at 40 points within and in the $300 \mathrm{~m}$ vicinity of the eddy footprint area (see Sect. 3.3, Fig. 1c) from single measurements of incoming and outgoing short-wave radiation under clear-sky conditions using a pyranometer. The resulting average albedo of $0.18 \pm 0.05$ compares well with the albedo of 0.15, which we infer from the time series of the BSRN station for the months of July and August. We use the latter value for our analysis, but assume an error of at least $5 \%$ on the net short-wave radiation, when the ground is snow-free. For the snow melt period, we assume an albedo estimate of 0.65 , which is the average albedo at the BSRN station between 1 and 15 June 2008. In this period, the snow melt occurred at the BSRN station, associated with a decrease in albedo from the winter value 0.8 to 0.5 , before it dropped sharply to the summer value. 
The outgoing and incoming long-wave radiation $L_{\text {out }}$ and $L_{\text {in }}$ are linked to the surface temperature $T_{\text {surf }}$ by

$L_{\text {out }}=\epsilon \sigma T_{\text {surf }}^{4}+(1-\epsilon) L_{\text {in }}$.

The emissivity $\epsilon$ is set to 0.96 for snow-free and 0.99 for snow-covered surfaces in this study (e.g. Rees, 1993; Bussières, 2002).

\subsection{Turbulent fluxes}

The turbulent land-atmosphere exchange fluxes of sensible and latent heat are measured with the eddy covariance method. The employed system consists of a Campbell CSAT 3D sonic anemometer and a fast-responding open-path LiCor LI-7500 $\mathrm{CO}_{2}$ and $\mathrm{H}_{2} \mathrm{O}$ gas analyzer, which are sampled at $20 \mathrm{~Hz}$ using a CR3000 Campbell Scientific datalogger. From the sonic temperature $T_{s}$, the specific humidity $q$ and the horizontal and vertical wind speed $u$ and $w$ measured at the eddy covariance system, the covariances $\overline{u^{\prime} w^{\prime}}, \overline{T_{s}^{\prime} w^{\prime}}$ and $\overline{q^{\prime} w^{\prime}}$ are calculated. They are then used to infer the momentum flux $\mathrm{u}_{*}^{2}$ and the sensible and latent heat flux $Q_{h}$ and $Q_{e}$ as (e.g Foken, 2008b).

$$
\begin{aligned}
u_{*}^{2} & =-\overline{u^{\prime} w^{\prime}} \\
Q_{h} & =c_{p} \rho_{\text {air }}\left(\overline{T_{s}^{\prime} w^{\prime}}-0.51 T_{\text {air }} \overline{q^{\prime} w^{\prime}}\right) \\
Q_{e} & =L_{\lg } \rho_{\text {air }} \overline{q^{\prime} w^{\prime}} .
\end{aligned}
$$

The evaluation is performed with the internationally standardized QA/QC software package "TK2" (Mauder and Foken, 2004; Mauder et al., 2008), which includes all "stateof-the-art" corrections and tests. For quality assessment of the flux measurements, we use the scheme of Foken et al. (2004) (see also Foken and Wichura, 1996), which is based on a steady-state and an integral turbulence characteristics test. However, the integral turbulence characteristics test is not well defined for intermittent turbulence and stable atmospheric conditions (Lüers and Bareiss, 2009a), which prevail during a large part of the study period. To achieve a consistent quality assessment, only the steady-state test is employed in this study. Hereby, the covariances $\overline{u^{\prime} w^{\prime}}, \overline{T_{s}^{\prime} w^{\prime}}$ and $\overline{q^{\prime} w^{\prime}}$ obtained for a 30-min interval are compared to the averages of the respective covariances calculated for 5-min subintervals. Stationary conditions can be assumed, if both results agree within $30 \%$, while a graduation of the deviation is used to classify the quality of the fluxes (Foken, 2008b).

At the 30-min timescale, the sensible heat flux $Q_{h}$ is considered in this study if both the quality flags for $\overline{u^{\prime} w^{\prime}}$ and $\overline{T_{s}^{\prime} w^{\prime}}$ feature a value of 6 or better, corresponding to flux measurements, which can be considered for long-term studies (Foken and Wichura, 1996). For the latent heat flux $Q_{e}$, the quality flags for $\overline{u^{\prime} w^{\prime}}$ and $\overline{q^{\prime} w^{\prime}}$ are used, respectively. Both for the sensible and the latent heat flux, approx. $15 \%$ of the values have been excluded due to the quality assessment. Furthermore, all flux values from wind sectors have been removed where the upwind tower structure could produce some flow distortions affecting the sonic anemometer (wind direction $15^{\circ}-55^{\circ}$ ). However, this applies only to about $1.5 \%$ of the flux values, as the tower structure is placed away from the prevailing wind directions. The half-hourly values are averaged to obtain a data set with an hourly resolution.

From 2 October to 18 October 2008 and from 1 January to 6 February 2009, the raw data sampled at $20 \mathrm{~Hz}$ were not recorded by the datalogger due to instrument failure. In these cases, fluxes based on preliminary, uncorrected 30-min covariances calculated by the standard datalogger software are used. Hereby, an adequate post-processing can not be applied and a subsequent quality assessment is not possible. However, the obtained flux values are considered in this study, because the standard datalogger software can reproduce the magnitude of the average fluxes for times when the sophisticated evaluation and quality assessment scheme is available.

For the snow-free period, the aerodynamic roughness length $z_{0}$ is estimated to be $7 \mathrm{~mm}$ from the measured values of $u_{*}$ and the horizontal wind speed during neutral atmospheric stratification conditions (e.g. Foken, 2008b). We then use the footprint model of Schmid (1994) to estimate the fetch area of the eddy covariance system. The average flux source area during the snow-free period from July to September 2008 is displayed in Fig. 1c. The main contributions originate from tundra areas in the prevailing wind directions from approx. $180^{\circ}$ (wind from the glacier Austre Brøggerbreen), approx. $110^{\circ}$ (wind from the inner Kongsfjorden) and from approx. $310^{\circ}$ to $350^{\circ}$ (wind from the outer Kongsfjorden).

To account for the changing height of the eddy covariance system due to accumulation or melting of snow, the snow depth at the eddy covariance site is recorded using an ultrasonic ranging sensor. From March to May 2008, the distance between the CSAT anemometer and the snow surface was around $1.0 \mathrm{~m}$. In the course of the snow melt, it increased to $2.1 \mathrm{~m}$, which was the measurement height of the CSAT during the snow-free time. From end of September 2008 onwards, the distance decreased again, but remained above $1.0 \mathrm{~m}$ until end of January 2009. Heavy snowfall led to a further decrease to around $0.5 \mathrm{~m}$ at the end of the study period. Paticularly flux data obtained at measurement heights below $1.0 \mathrm{~m}$ may bear a considerable uncertainty due to highfrequency losses (e.g. Moore, 1986) or drifting snow affecting the sonic anemometer (Lüers and Bareiss, 2009a). However, since the quality assessment still indicates a good overall data quality and the magnitude of the measured fluxes matches well with periods, where the measurement height was considerably above $1.0 \mathrm{~m}$, the data are considered for this study.

\subsection{Ground heat flux}

In the context of the surface energy budget, we are interested in the heat flux through the interface between the atmosphere and the ground or snow, respectively. The latter is denoted snow heat flux in the following. Two different methods are 
employed to calculate the ground or snow heat flux. The first method, which we refer to as the bulk method, was successfully applied at the study site by Boike et al. (2003b), where it is described in detail. It is based on differences in the absolute sensible and latent heat content of the soil and snow column, from which an average ground or snow heat flux for the considered time interval can be calculated. The water content of the soil and thus the latent heat content is compiled from a profile of seven Time Domain Reflectometry (TDR) measurements located next to a profile of temperature measurements (P1 in Fig. 1c), from which the sensible heat content is derived. No measurements exist for a potential non-zero water and thus latent heat content of the snow pack. Therefore, the snow is completely excluded from the evaluation during the snow melt period (see Sect. 3.5). The latent heat added to the snow pack by so-called "rain-on-snow"-events during winter (Putkonen and Roe, 2003) is estimated from precipitation records (see Sect. 3.6). This is justified, since no run-off occurs during these events and the entire amount of water refreezes subsequently. Using the specific latent heat of fusion, $L_{\mathrm{sl}}$, the total heat input through rain-on-snow events can be calculated, which is then converted to an average flux.

The bulk method is well suited to deliver reliable average fluxes for longer periods, but has short-comings on the timescale of one hour due to the limited number of temperature and soil moisture sensors, which cannot resolve the temperature distribution in the uppermost soil column. Furthermore, the maximum active layer thickness was around $1.5 \mathrm{~m}$ during the study period, which is well below the deepest TDR sensor, located at $1.13 \mathrm{~m}$. Therefore, the fluxes are biased, when the soil below the deepest TDR sensor thaws or freezes, which mainly affects the thaw period in August and September 2008 and the following refreezing period in October and November 2008.

The second method directly calculates the ground heat flux through the surface by solving the differential equation of conductive heat transport. It is referred to as the conduction method (see Appendix A). Although convective heat transport, e.g. through infiltrating rain water, is not accounted for, the assumption of a conductive heat transfer was shown to be adequate for the study area during winter (Roth and Boike, 2001), a site approx. $10 \mathrm{~km}$ from the study area (Putkonen, 1998) and for other permafrost areas (e.g. Romanovsky and Osterkamp, 1997). Periods, where a phase change of water occurs within the considered soil column, are excluded from the evaluation. To evaluate the thermal diffusivity $d_{h}$, the heat capacity $c_{h}$ and the thermal conductivity $K_{h}$ of the soil during the snow-free period, we use the shallow temperature profile P2 (Fig. 1c, Table 1).

The thermal diffusivity is fitted for different periods in July and August 2008, with values ranging from $d_{h}=$ $5.2 \times 10^{-7} \mathrm{~m}^{2} \mathrm{~s}^{-1}$ to $d_{h}=6.5 \times 10^{-7} \mathrm{~m}^{2} \mathrm{~s}^{-1}$. For the fit, we exclude periods with measurement errors or strong rain events, which may induce non-conductive transport of heat. The found variability of $d_{h}$ may at least partly originate
Table 1. Installations of the temperature profiles used to calculate the ground heat flux; $z_{\min }, z_{\max }$ : minimum and maximum depths of the temperature sensors; Th: thermistor; TC: type T thermocouple; PT100: platinum resistance temperature sensor; TDR: measurement of soil water content using Time Domain Reflectometry.

\begin{tabular}{lccc}
\hline profile & $\mathrm{P} 1$ & $\mathrm{P} 2$ & $\mathrm{P} 3$ \\
\hline$z_{\min } / \mathrm{m}$ & 0.02 & 0.01 & 0.01 \\
$z_{\max } / \mathrm{m}$ & 1.55 & 0.25 & 0.30 \\
soil & $7 \times \mathrm{PT} 100$, & $1 \times \mathrm{Th}$, & $2 \times \mathrm{Th}$, \\
& $6 \times \mathrm{TDR}$ & $2 \times \mathrm{TC}$ & $1 \times \mathrm{TC}$ \\
snow & $2 \times \mathrm{PT} 100$ & $3 \times \mathrm{TC}$ & $3 \times \mathrm{TC}$ \\
installed & $09 / 01 / 1998$ & $07 / 07 / 2008$ & $10 / 01 / 2008$ \\
\hline
\end{tabular}

from natural processes, e.g. through changing soil water content. For the evaluation of the ground heat fluxes in the snow-free period, we apply a constant value $d_{h}=$ $(5.5 \pm 1.0) \times 10^{-7} \mathrm{~m}^{2} \mathrm{~s}^{-1}$.

In soil samples collected in the vicinity of the temperature profiles, the volumetric bulk (mineral and organic) content was determined to be between $45 \%$ and $65 \%$, and the volumetric soil water content varied between $20 \%$ and $40 \%$. Thus, the heat capacity of the soil can be estimated to $c_{h}=(2.3 \pm 0.5) \mathrm{MJm}^{-3}$, which results in a thermal conductivity of $K_{h}=(1.3 \pm 0.4) \mathrm{Wm}^{-1} \mathrm{~K}^{-1}$. The value is well within the range predicted by widely-used models such as the de-Vries-model (De Vries, 1952; Campbell et al., 1994) for such soils. With $\mathrm{K}_{h}$ known, the ground heat flux can be evaluated (see Appendix A). Note, that the considerable uncertainties on both $d_{h}$ and $c_{h}$ propagate to $K_{h}$, resulting in an uncertainty of more than $25 \%$ for the obtained ground heat flux.

During the winter 2008/2009, a profile of three temperature sensors (located at the soil surface and $0.15 \mathrm{~m}$ and $0.4 \mathrm{~m}$ above the surface) in the snow pack located next to P3 is used to fit the thermal diffusivity of the snow. This is possible from December 2008 onwards, as soon as the snow pack has reached the uppermost sensor. Initially, the array is contained in the young snow pack, but gets progressively buried with increasing snow height. The obtained values range from $d_{h}=4.5 \times 10^{-7} \mathrm{~m}^{2} \mathrm{~s}^{-1}$ to $d_{h}=$ $7.0 \times 10^{-7} \mathrm{~m}^{2} \mathrm{~s}^{-1}$, with a tendency towards higher values of $d_{h}$ at the end of the considered period for the then older snow. However, we have no measurements of the thermal diffusivity of the overlying, not instrumented snow pack. For the evaluation of the snow heat flux, we therefore choose a constant value of $d_{h}=(5.5 \pm 1.5) \times 10^{-7} \mathrm{~m}^{2} \mathrm{~s}^{-1}$ and include the found variability of $d_{h}$ as uncertainty. In March 2009, snow density profiles were gravimetrically measured in increments of $0.1 \mathrm{~m}$ at five sites in the eddy fetch area and in its vicinity. The average snow density was determined to $\rho_{\text {snow }}=(0.37 \pm 0.05) \mathrm{gcm}^{-3}$, which results in a heat 
capacity $c_{h \text {, snow }}=(0.75 \pm 0.1) \mathrm{MJm}^{-3} \mathrm{~K}^{-1}$ (using $c_{h \text {, snow }}=$ $\left.c_{h \text {,ice }} \times \rho_{\text {snow }} / \rho_{\text {ice }}\right)$. Hence, the resulting snow conductivity is $K_{h}=(0.45 \pm 0.15) \mathrm{Wm}^{-1} \mathrm{~K}^{-1}$.

Since the temperature sensors are placed at fixed heights above the ground, it is only possible to infer the heat flux within the snow pack up to the height of the uppermost sensor, which is clearly different from the targeted heat flux through the snow surface. Therefore, the snow surface temperatures inferred from measurements of long-wave radiation (Eq. 1) at the Bayelva climate station, next to P1, are used as upper boundary condition, while temperatures at the snow-soil interface at P1 are used as lower boundary. The snow heat flux is then calculated (see Appendix A) for periods defined by snow heights that fall within classes of $0.1 \mathrm{~m}$ increments. The snow height is measured next to P1 with an ultrasonic ranging sensor. This method induces discontinuities in the flux at the boundary of each two periods, so the flux values have to be discarded at these boundaries. The obtained snow heat flux is associated with an error of approx. $30 \%$, which mainly originates from the uncertainty in the thermal conductivity. It must be emphasized that the snow pack is treated as homogeneous in time and space, which does not reflect processes such as aging and densification of the snow. However, at least the snow density measurements indicate a homogeneous snow pack, both for each profile and among different locations.

When a rain-on-snow event occurs, the fluxes are discarded, until all measured temperatures in the snow decrease below $-0.5^{\circ} \mathrm{C}$ and refreezing processes can be excluded. This leads to the exclusion of in total seven days during the winter 2008/2009. Particularly the strong rain-on-snow events provoke a pronounced warming of the underlying soil column, which then slowly cools by means of conductive heat transport through the snow. Therefore, the conduction method accounts for at least some part of the heat input through rain-on-snow events, although the time directly after the rain-and-snow events is excluded.

\subsection{Melt energy of the snow}

During snow melt, the latent heat consumed by the melting snow $Q_{\text {melt }}$ appears as an additional component in the surface energy budget. Between 25 May and 28 May 2008, before the onset of the snow melt, the snow water equivalent of the snow at the study site was estimated by seven snow density measurements and systematic snow depth measurements on a $20 \times 20$ square meter grid. With the specific latent heat of fusion, $L_{\mathrm{sl}}$, the total energy required to melt the snow can be evaluated, which is then converted to an average flux for the snow melt period. A considerable uncertainty is induced by a basal ice layer underneath the snow, which has not been spatially surveyed.

\subsection{Ancillary measurements}

We use the detailed record of the Norwegian Meteorological Institute from the village of $\mathrm{Ny}$-Ålesund (Fig. 1b) for data on precipitation, air pressure, relative humidity and cloud fraction (eklima, 2009). The air temperature at $2 \mathrm{~m}$ height above ground is measured at the Bayelva climate station. The precipitation is recorded at the study site with an unheated RM Young 52203 Tipping Bucket rain gauge, which can only measure precipitation in the form of rain and possibly slush. These data are used as a coarse estimate for the amount of liquid precipitation during the winter season, from which we obtain the energy input through rain-on-snow events (see Sect. 3.4).

From October 2008 to March 2009, measurements of the air temperature at $2 \mathrm{~m}$ and $10 \mathrm{~m}$ above ground, denoted $T_{\text {air }}(2 \mathrm{~m})$ and $T_{\text {air }}(10 \mathrm{~m})$, were performed approx. $150 \mathrm{~m}$ from the location of the eddy covariance system (Fig. 1c) to obtain additional data on the atmospheric stratification. With increasing snow height, the distances of the sensors to the snow surface decreased accordingly, with the lower temperature sensor being approximately at the same height above the surface as the eddy covariance system (see Sect. 3.3).

\section{Results}

The one year study period is divided into six segments, each of which feature distinct characteristics of the surface energy budget. The transition between different segments is mostly gradual, but the segmentation is closely orientated at "real" events, such as the onset or termination of the snow melt or the beginning of the polar night. The average fluxes for each of the segments are presented in Table 2.

\subsection{Summer (1 July 2008-31 August 2008)}

The summer period is characterized by a strong forcing by short-wave radiation and the absence of the seasonal snow cover. The net short-wave radiation $\Delta S$ is compensated by the net long-wave radiation, the sensible and latent heat flux, and the ground heat flux, which leads to the seasonal thawing of the active layer (Fig. 2, Table 2). Cloudy conditions are typical for the summer season (Table 2), which effectively reduces the incoming solar radiation. The difference in $\Delta S$ between cloud-covered and clear skies can exceed $150 \mathrm{Wm}^{-2}$ in the daily average. On the other hand, the incoming longwave radiation $L_{\text {in }}$ increases during cloudy periods, with daily average differences of around $80 \mathrm{Wm}^{-2}$. The absolute values of $L_{\text {in }}$ range from $-230 \mathrm{Wm}^{-2}$ to $-340 \mathrm{Wm}^{-2}$, while the outgoing long-wave radiation $L_{\text {out }}$ ranges from $300 \mathrm{Wm}^{-2}$ to $400 \mathrm{Wm}^{-2}$, corresponding to surface temperatures between $-5^{\circ} \mathrm{C}$ and $+17^{\circ} \mathrm{C}$ (Eq. 1).

A measure for the atmospheric stability is the dimensionless parameter $\xi=z / L$, which is obtained from the sonic anemometer ( $L$ Obukhov-length, $z$ measurement height). 
Table 2. Average values for air temperature $T_{\text {air }}$, precipitation $P$, air pressure $p$, relative humidity RH, cloud fraction cf. (see Sect. 3.6) and for the various contributions of the surface energy budget (see Sect. 3.1) for different segments of the study period. Values in parentheses are estimates or based on data records with frequent data gaps. The value for $Q_{g}$ bulk during dark winter is composed of the flux due to the refreezing of the active layer, $-5.0 \mathrm{Wm}^{-2}$, and a flux of $-1.8 \mathrm{Wm}^{-2}$ due to rain-on-snow events.

\begin{tabular}{lrrrrrrr}
\hline & Summer & Fall & Dark winter & Light winter & Pre-melt & Snow melt & Total \\
\hline & $07 / 01 / 08$ & $09 / 01 / 08$ & $10 / 01 / 08$ & $03 / 15 / 08$ & $04 / 16 / 08$ & $06 / 01 / 08$ & $03 / 15 / 08$ \\
& $-08 / 31 / 08$ & $-09 / 31 / 08$ & $-03 / 15 / 09$ & $-04 / 15 / 08$ & $-05 / 31 / 08$ & $-06 / 30 / 08$ & $-03 / 15 / 09$ \\
\hline$T_{\text {air }} /{ }^{\circ} \mathrm{C}$ & 5.0 & 2.7 & -10.1 & -16.0 & -5.6 & 2.0 & -5.4 \\
$\mathrm{P} / \mathrm{mm}$ & 32 & 99 & 278 & 12 & 11 & 8 & 440 \\
$\mathrm{p} / \mathrm{hPa}$ & 1011 & 1008 & 1004 & 1017 & 1018 & 1014 & 1009 \\
$\mathrm{RH}$ & $82 \%$ & $81 \%$ & $73 \%$ & $59 \%$ & $71 \%$ & $73 \%$ & $74 \%$ \\
$\mathrm{cf}$ & $6.4 / 8$ & $6.9 / 8$ & $5.5 / 8$ & $3.6 / 8$ & $5.7 / 8$ & $5.5 / 8$ & $5.6 / 8$ \\
$S_{\mathrm{in}} / \mathrm{Wm}^{-2}$ & -144 & -33 & -2.1 & -73 & -185 & -261 & -78 \\
$S_{\text {out }} / \mathrm{Wm}^{-2}$ & 22 & 9 & 1.7 & 55 & 144 & $(170)$ & 42 \\
$\Delta S / \mathrm{Wm}^{-2}$ & -122 & -24 & -0.4 & -18 & -41 & $(-91)$ & -36 \\
$L_{\mathrm{in}} / \mathrm{Wm}^{-2}$ & -303 & -299 & -234 & -196 & -255 & -276 & -254 \\
$L_{\text {out }} / \mathrm{Wm}^{-2}$ & 346 & 318 & 262 & 237 & 288 & 319 & 286 \\
$\Delta \mathrm{L}^{-2} \mathrm{Wm}^{-2}$ & 43 & 19 & 28 & 41 & 33 & 43 & 32 \\
$Q_{h} / \mathrm{Wm}^{-2}$ & 22.5 & $(-7)$ & -16 & -18 & -8 & -6 & -6.9 \\
$Q_{e} / \mathrm{Wm}^{-2}$ & 22.5 & $(9)$ & 2.5 & 0.7 & 2.5 & 11 & 6.8 \\
$\mathrm{Q}_{\text {gbulk }} / \mathrm{Wm}^{-2}$ & $(11)$ & - & $(-5.0)-1.8$ & -3.1 & 3.0 & 13 & $\sim 0.5$ \\
$\mathrm{Q}_{\text {g cond }} / \mathrm{Wm}^{-2}$ & 12 & $(0.6)$ & -5.0 & -5.9 & - & - & 2.3 \\
$\mathrm{Q}_{\text {melt }} / \mathrm{Wm}^{-2}$ & $?$ & $?$ & 0 & 0 & 0.5 & $(27)$ & 3 \\
$\mathrm{C} / \mathrm{Wm}{ }^{-2}$ & 22 & 2 & -9 & 0 & 10.5 & 1 \\
\hline
\end{tabular}

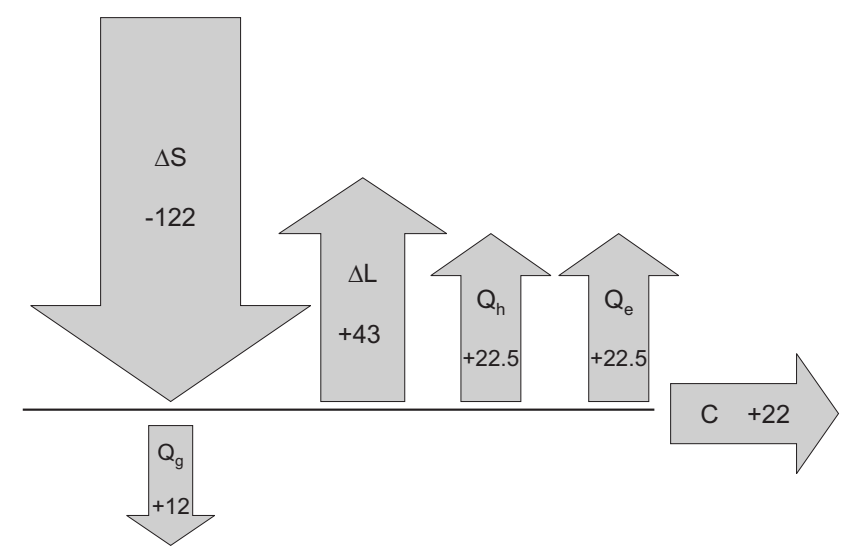

Fig. 2. Schematic diagram of the contributions of the surface energy budget for the summer period. The area of the arrows is proportional to the relative importance in the energy budget. Arrows pointing away from the surface indicate positive fluxes. The flux values are given in $\mathrm{Wm}^{-2}$.

Positive values indicate stable, while negative values represent unstable atmospheric stratifications. During the polar day season, approx. until mid of August, the atmospheric stratification is either unstable or neutral. Later, the general situation can be characterized as neutral to weakly unstable atmospheric stratification during the day and stable atmo- spheric stratification during the night. The sensible, latent and ground heat fluxes are shown in Fig. 3. The average Bowen ratio is approximately one, but it shows strong variations, which are closely related to the soil water content of the surface layer (Figs. 3, 4). For a wide range of intermediate soil moisture conditions, it remains around one, but extremely wet or dry conditions lead to Bowen ratios of around 0.25 or 2 , respectively (Fig. 4). The sensible and the latent heat flux display a strong diurnal amplitude, with peak fluxes between $60 \mathrm{Wm}^{-2}$ and $120 \mathrm{Wm}^{-2}$ associated with maxima of net radiation around midday. At the lowest sun angles, around midnight, the absolute values of both fluxes decrease to close to zero, but usually remain positive. The latent heat flux observed in July and August 2008 corresponds to a total evaporation of $48 \mathrm{~mm}$, which is significantly more than the precipitation of $32 \mathrm{~mm}$ recorded during the same period. This can be related to the drying of the water-saturated tundra after snow melt. The average ground heat fluxes peaks at the beginning of the summer period, when the thaw front is close to the soil surface and a strong temperature gradient exists in the soil. Peak values are around $60 \mathrm{Wm}^{-2}$, which is of comparable magnitude as the sensible and latent flux (Fig. 3). However, the storage effect of the soil is reflected in generally negative ground heat fluxes of up to $-30 \mathrm{Wm}^{-2}$ during night times (i.e. times with low solar angle during polar day), so that the average ground heat flux is considerably less than the average sensible and latent heat flux (Fig. 2, Table 2). 


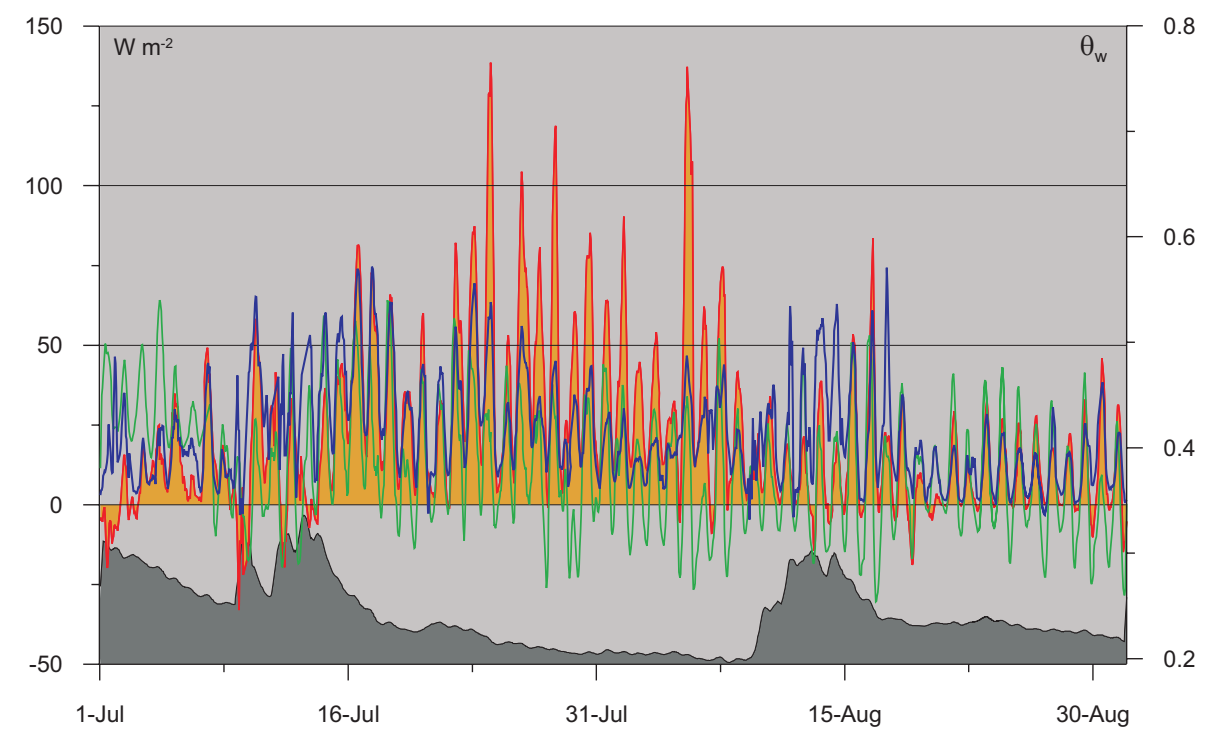

Fig. 3. Sensible (red), latent (blue) and ground heat fluxes (green) for the summer period from 1 July to 31 August 2008 (left axis). The soil water content $\theta_{w}$ measured with Time Domain Reflectometry at a depth of $0.1 \mathrm{~m}$ at the Bayelva climate station is shown below (right axis).

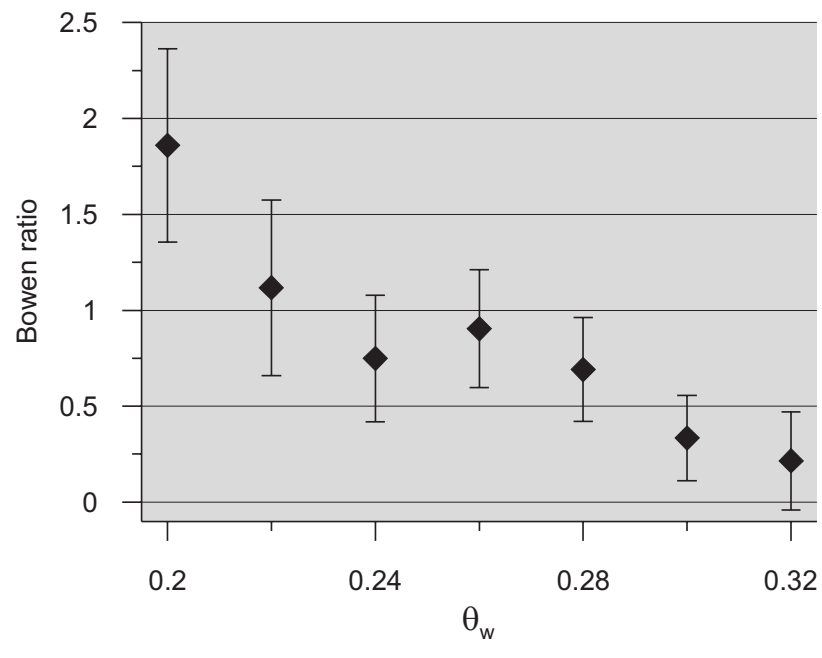

Fig. 4. Average daily Bowen ratio vs. volumetric soil water content $\theta_{w}$ in soil water content classes of widths of 0.02 for the summer period from 1 July to 31 August 2008 (see Fig. 3). The points are drawn at the center of each class, and the error bars represent the standard deviation of the Bowen ratio values within one class. Three days with negative average $Q_{h}$ are discarded.

An energy balance closure term of $22 \mathrm{Wm}^{-2}$ remains. This residual typically appears in energy budget studies (Foken, 2008a), possible reasons are discussed in Sect. 5.1.

\subsection{Fall (1 September 2008-30 September 2008)}

During fall, the net short-wave radiation strongly decreases due to the much lower solar angles, but a permanent snow cover has not yet formed and a sustained refreezing of the active layer has not started. September 2008 was characterized by a series of cyclones, which transported warm air masses from the south and led to strong precipitation. At NyÅlesund, $99 \mathrm{~mm}$ of precipitation were recorded, almost entirely as rain, which is more than twice of the usual September precipitation. The many rain events resulted in frequent data gaps and generally poor data quality regarding the eddy covariance measurements, but the general magnitude of the average fluxes should still be correctly reproduced.

The observed latent heat flux (Fig. 5, Table 2) corresponds to an evaporation of $9 \mathrm{~mm}$ during the fall period, so that the precipitation is not even roughly balanced by the evaporation. As a consequence, the water content of the soil is increased compared to the summer season, just before the soil starts to freeze. Most likely, this process still occurs, when the precipitation during September is not unusually high. Other than during summer, the sensible heat flux is on average negative, i.e. the advection of relatively warm air results in a warming of the surface. The average ground heat flux is still positive, corresponding to a transport of energy in the ground, which results in a further increase of the active layer depth.

In 2008, the perennial snow cover formed on 29 September, when the average incoming short-wave radiation at the Bayelva station had decreased to approx. $-12 \mathrm{Wm}^{-2}$ (average data from 25 September to 5 October 2008).

\subsection{Dark winter (1 October 2008-15 March 2009)}

The short-wave radiation is essentially zero during this period (Fig. 6, Table 2), as it mostly falls within the polar night, which lasts from 25 October until 14 February at the 


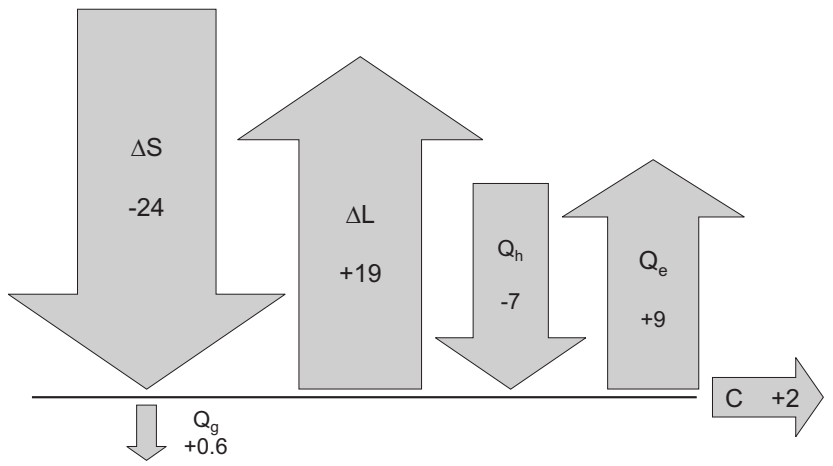

Fig. 5. Schematic diagram of the contributions of the surface energy budget for the fall period. Notation as in Fig. 2.

study site. The peak values of $\Delta S$ during midday at the very beginning and end of the dark winter period are around $-20 \mathrm{Wm}^{-2}$. In the absence of short-wave radiation, the long-wave radiation becomes the main forcing of the system. Between October 2008 and March 2009, $L_{\text {in }}$ ranges from $-140 \mathrm{Wm}^{-2}$ to $-320 \mathrm{Wm}^{-2}$, while $L_{\text {out }}$ is between $190 \mathrm{Wm}^{-2}$ and $320 \mathrm{Wm}^{-2}$. For the entire period, the absolute value of $L_{\text {in }}$ is found to be equal or smaller than $L_{\text {out }}$. With an average value of $28 \mathrm{Wm}^{-2}$, the net long-wave radiation represents the dominant energy loss term during dark winter.

The net long-wave radiation is mainly compensated by a negative average sensible heat flux, corresponding to a warming of the surface and a cooling of the atmosphere. With an average of $-16 \mathrm{Wm}^{-2}$, the sensible heat flux is a strong supply of energy to the snow surface. In addition, the snow heat flux compensates for about $20 \%$ of the energy loss by net long-wave radiation. The latent heat flux is found to be of minor importance in the overall surface energy budget during the dark winter period (Fig. 6, Table 2). A residual term of $-9 \mathrm{Wm}^{-2}$ remains.

During the dark winter period, we estimate about $80 \mathrm{~mm}$ of rain, which fell to great parts during three rain-on-snow events in October 2008, January 2009 and February 2009. This corresponds to an average heat flux of $-1.8 \mathrm{Wm}^{-2}$ (see Sect. 3.4) and is thus significant compared to the heat flux supplied by the refreezing active layer, which is about $-5 \mathrm{Wm}^{-2}$ (bulk method for $Q_{g}$ ).

The incoming long-wave radiation is clearly the determining factor for the temperature of the snow surface and hence for the outgoing long-wave radiation (Fig. 7), but a significant influence of other factors, particularly of the wind speed, remains. At high wind speeds, atmospheric turbulence is mechanically induced. This facilitates the exchange of energy between the surface and the warmer atmosphere, so that the surface temperature is sustained at higher values (Fig. 7). The influence of the wind speed is clearly less pronounced for large values of $L_{\text {in }}$ and high surface temperatures. A possible explanation is that the gradient between the air and the

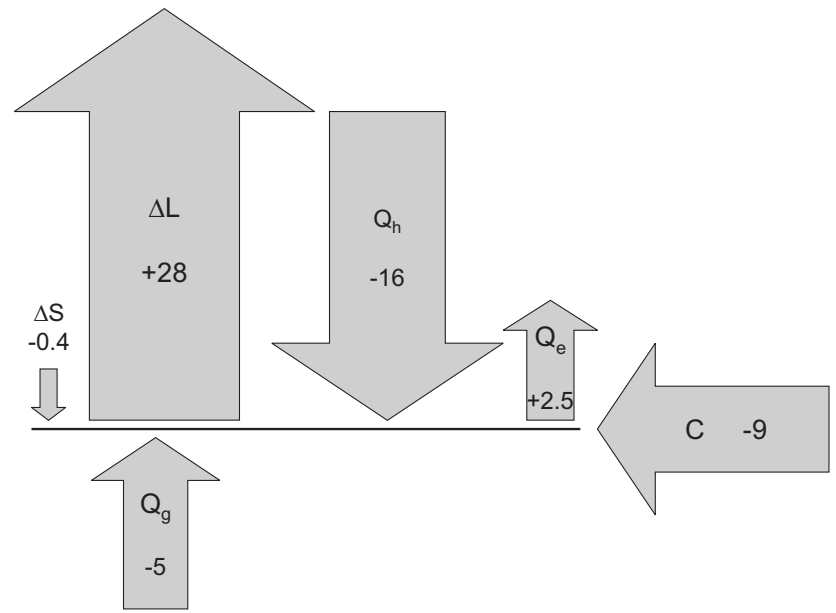

Fig. 6. Schematic diagram of the contributions of the surface energy budget for the dark winter period. Notation as in Fig. 2.

snow surface temperature is generally small in these cases, which prevents a strong exchange of energy independent of the formation of turbulence.

Throughout the entire dark winter period, strong sensible fluxes around $-30 \mathrm{Wm}^{-2}$ to $-70 \mathrm{Wm}^{-2}$ are associated with high wind speeds, which cause neutral or only weakly stable atmospheric stratifications, with a stability parameter $\xi=z / L$ close to zero. When wind speeds are low, a stable stratification and a strong near-surface temperature inversion can form, which significantly reduces the fluxes between surface and atmosphere. This is illustrated in Fig. 8, which shows surface temperature, wind speed, air temperature inversion between $9.3 \mathrm{~m}$ and $1.3 \mathrm{~m}$ height and the fluxes $Q_{h}$, $Q_{e}$ and $Q_{g}$ for a period with approximately constant $L_{\text {in }}$ of around $-180 \mathrm{Wm}^{-2}$. Initially, the wind speed is low and a stable atmospheric stratification or even an inversion layer close to the surface exists, which prevents a significant sensible heat flux. Thus, the surface temperature can not be sustained and starts to decrease to a minimum value of $-18^{\circ} \mathrm{C}$. This increases the temperature gradient across the snow pack and hence triggers a strong snow heat flux, which moderates the drop in surface temperature. Around 27 November, an increase in wind speed breaks up the stable stratification, and significant sensible heat fluxes of up to $-50 \mathrm{Wm}^{-2}$ stabilize the surface temperature around $-15^{\circ} \mathrm{C}$. Decreasing wind speeds around 29 November again lead to a stable atmospheric stratification, with an associated drop in surface temperature to about $-23^{\circ} \mathrm{C}$.

Even during the polar night, considerable latent heat fluxes of up to $30 \mathrm{Wm}^{-2}$ occur, mainly at high wind speeds and neutral atmospheric stratifications (see Fig. 8). These positive fluxes correspond to a cooling of the surface through sublimation of snow or, when present, evaporation of water. Particularly at stable stratifications, negative latent heat fluxes of up to $-5 \mathrm{Wm}^{-2}$ are detected (Fig. 8). Hence, a limited 


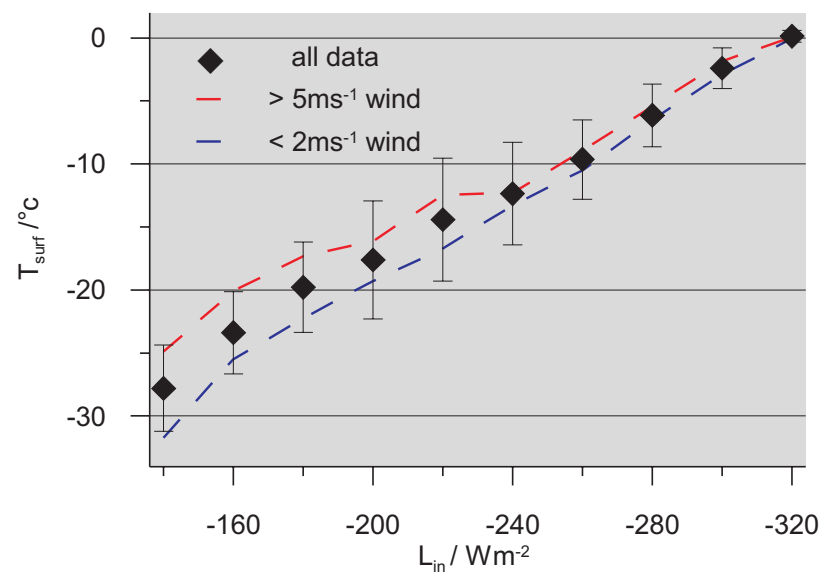

Fig. 7. Surface temperature $T_{\text {surf }}$ vs. incoming long-wave radiation $L_{\text {in }}$ during the dark winter period in classes of $L_{\text {in }}$ of $20 \mathrm{Wm}^{-2}$ width. The points are drawn at the center of each class, and the error bars represent the standard deviation of the surface temperature values within one class. The red and blue lines represent the average curves for situations with high and low wind speeds.

amount of condensation or resublimation occurs, but its contribution to the total energy budget is insignificant. The total net sublimation or evaporation during dark winter amounts to $30 \mathrm{~kg} \mathrm{~m}^{-2}$, which corresponds to a snow column of almost $0.1 \mathrm{~m}$ at the recorded snow densities (see Sect. 3.4 and 3.5).

The snow heat flux is of great importance, particularly when a stable atmospheric stratification limits the sensible heat flux. Then, the snow heat flux becomes the dominant energy supply. The refreezing active layer provides a weak, but constant flux of energy, which is reflected in a negative average heat flux through the snow surface. Nevertheless, the storage effect of the snow and strong fluctuations of the surface temperature result in both positive and negative snow heat fluxes at the snow surface.

A strong stable atmospheric stratifications occurs frequently, but usually does not last longer than a few days. The stability parameter $\xi=z / L$ exceeds values of 0.5 in about $15 \%$ of the time, while values greater than 5 have only been recorded in about $1 \%$ of the time. During stable stratifications, the temperature inversion in the lowest $10 \mathrm{~m}$ of the atmosphere can be considerable, so that an average difference of $+0.8 \mathrm{~K}$ could be calculated between the air temperatures at $10 \mathrm{~m}$ and $2 \mathrm{~m}$ height (Fig. 9). An even more pronounced temperature inversion is found between the surface temperature and the air temperature measured at different heights, i.e. $T_{\text {air }}(2 \mathrm{~m})$ and $T_{\text {air }}(10 \mathrm{~m})$, where temperature differences of more than $5 \mathrm{~K}$ are common (Fig. 9).

\subsection{Light winter (15 March 2008-15 April 2008)}

The net short-wave radiation is rapidly increasing in light winter, although its role is still limited due to the high snow

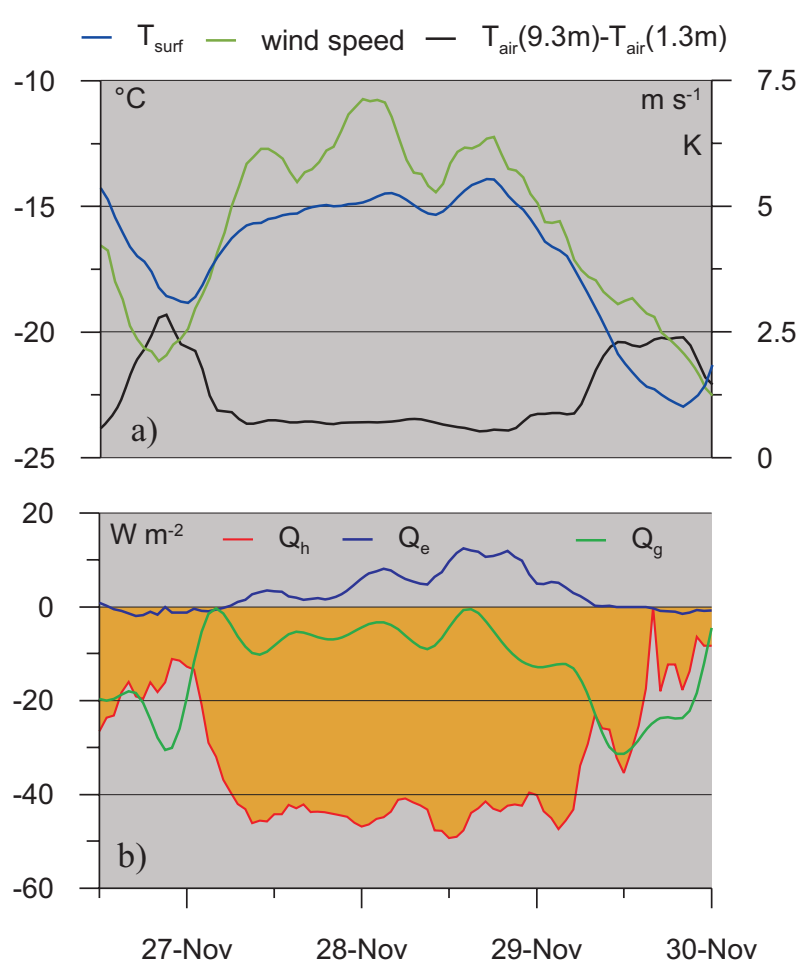

Fig. 8. (a) Surface temperature (left axis), wind speed (right axis), and temperature difference at the gradient tower (right axis) for a period in November 2008. The snow depth was $0.7 \mathrm{~m}$ at this time. (b) Sensible heat flux $Q_{h}$, latent heat flux $Q_{e}$ and snow heat flux $Q_{g}$ (conduction method) for the same period.

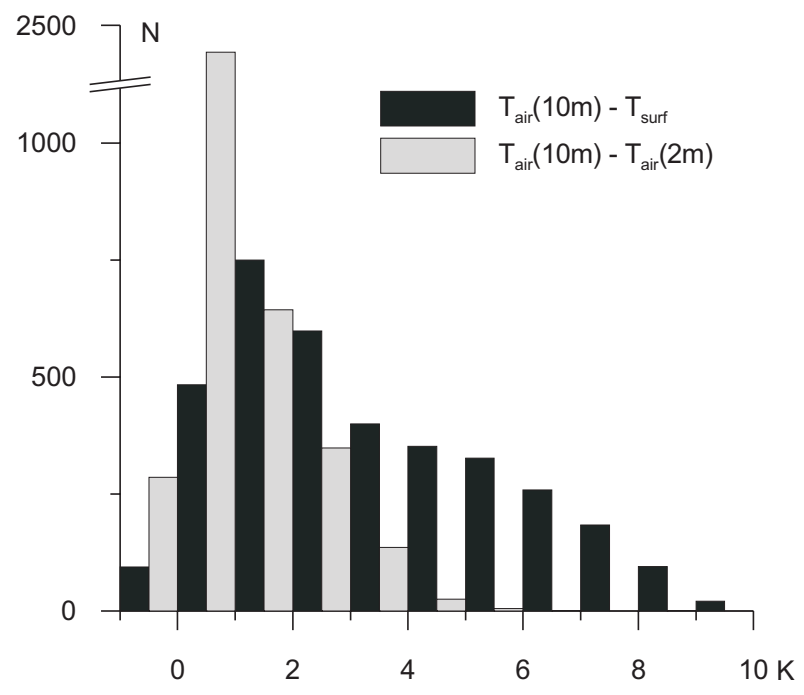

Fig. 9. Number of hourly values during the dark winter period $\mathrm{N}$ vs. temperature difference (in classes of $1 \mathrm{~K}$ ) between air temperature at $10 \mathrm{~m}$ height and air temperature at $2 \mathrm{~m}$ height, and air temperature at $10 \mathrm{~m}$ height and surface temperature, respectively. Due to the snow accumulation, the heights decreased from $10 \mathrm{~m}$ to $8.8 \mathrm{~m}$ and $2.0 \mathrm{~m}$ to $0.8 \mathrm{~m}$ during the considered period. 


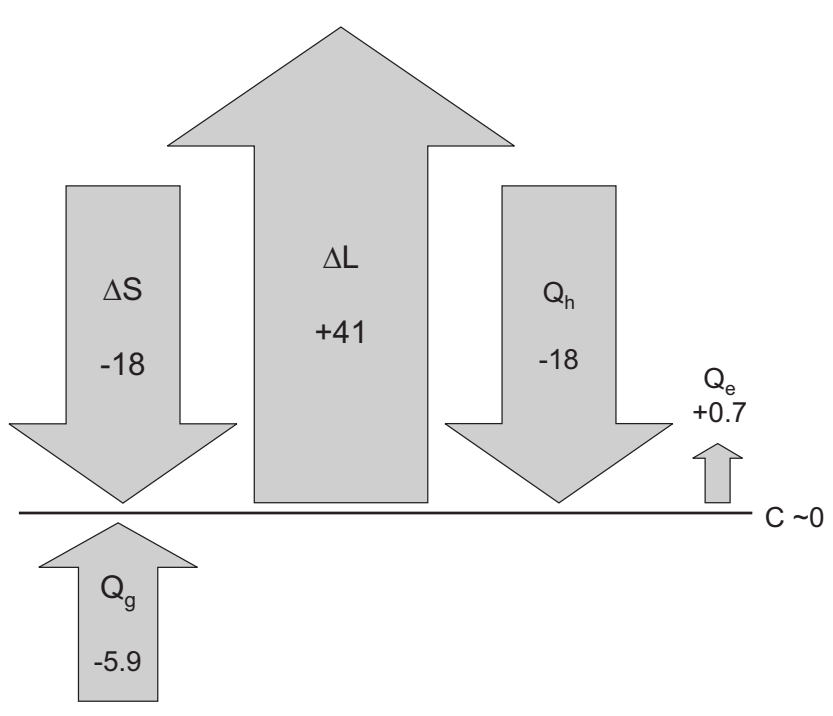

Fig. 10. Schematic diagram of the contributions of the surface energy budget for the light winter period. Notation as in Fig. 2.

albedo of about 0.8 . Other than that, the surface energy budget very much resembles the dark winter period: the energy loss through the net long-wave radiation is compensated to equal parts by the sensible heat flux and the short-wave radiation (Fig. 10, Table 2). The snow heat flux still remains negative, corresponding to a further cooling of the underlying soil column. At the end of the light winter period, the lowest soil temperatures are reached, with about $-8^{\circ} \mathrm{C}$ at the soil surface and $-4{ }^{\circ} \mathrm{C}$ at $1.5 \mathrm{~m}$ depth.

\subsection{Pre-melt period (16 April 2008-31 May 2008)}

From mid of April, the net short-wave radiation $\Delta S$ becomes the dominant energy supply, with an average of $-41 \mathrm{Wm}^{-2}$ (Fig. 11, Table 2). The sensible heat flux provides an additional energy of $-8 \mathrm{Wm}^{-2}$, while the net long-wave radiation $\Delta L$ is the main balancing factor, with an average of $33 \mathrm{Wm}^{-2}$. The latent heat flux is positive, but remains insignificant with an average of $2.5 \mathrm{Wm}^{-2}$. The snow and soil column start to gradually warm during the pre-melt period, which is reflected in a now positive average snow heat flux. A positive residual of around $10 \mathrm{Wm}^{-2}$ remains, which largely builds up at the end of the pre-melt period. This indicates that melting of the snow already occurs, which is not accounted for in the surface energy budget during the pre-melt period. One snow melt event has indeed been observed on 30 May. Hereby, the temperature sensor at the snow-soil interface at $\mathrm{P} 1$ recorded a rapid temperature increase of $2 \mathrm{~K}$ within a few hours, which can only be explained by infiltrating melt water. In addition to this single strong melt event, it is possible that more snow melt occurs close to the surface without causing detectable melt water infiltration.

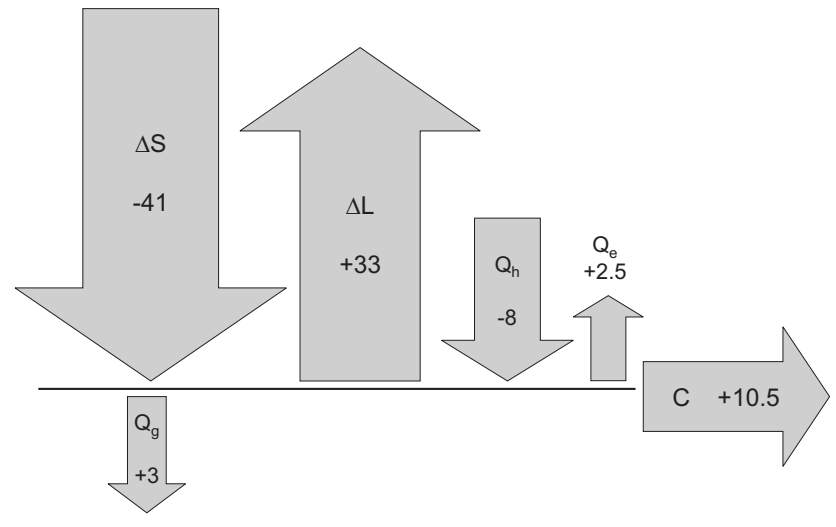

Fig. 11. Schematic diagram of the contributions of the surface energy budget for the pre-melt period. Notation as in Fig. 2.

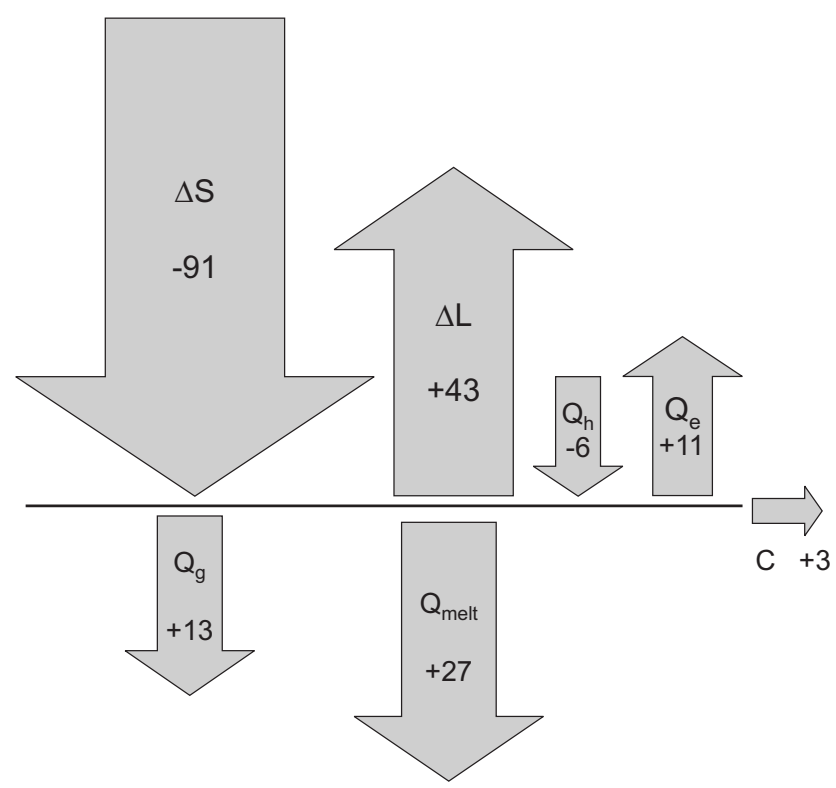

Fig. 12. Schematic diagram of the contributions of the surface energy budget for the snow melt period. Notation as in Fig. 2.

\subsection{Snow melt (1 June 2008-30 June 2008)}

The warming of the snow pack towards $0{ }^{\circ} \mathrm{C}$ at the end of the pre-melt period is followed by the period of snow melt. Hereby, the energy consumed by the phase change of the melting snow appears as a dominant component in the energy budget (Fig. 12, Table 2). The average snow density before snow melt in 2008 was found to be $0.35 \mathrm{~g} \mathrm{~cm}^{-3}$, with an average snow depth of $0.6 \mathrm{~m}$. Thus, the average latent heat stored in the snow pack amounts to $70 \mathrm{MJm}^{-2}$, which yields an average energy consumption of $27 \mathrm{Wm}^{-2}$ for the time between 1 June and 30 June, during which most of the snow melt occurred in 2008.

The net short-wave radiation $\Delta \mathrm{S}$ increases considerably (Fig. 12, Table 2) despite of the still high albedo of the 


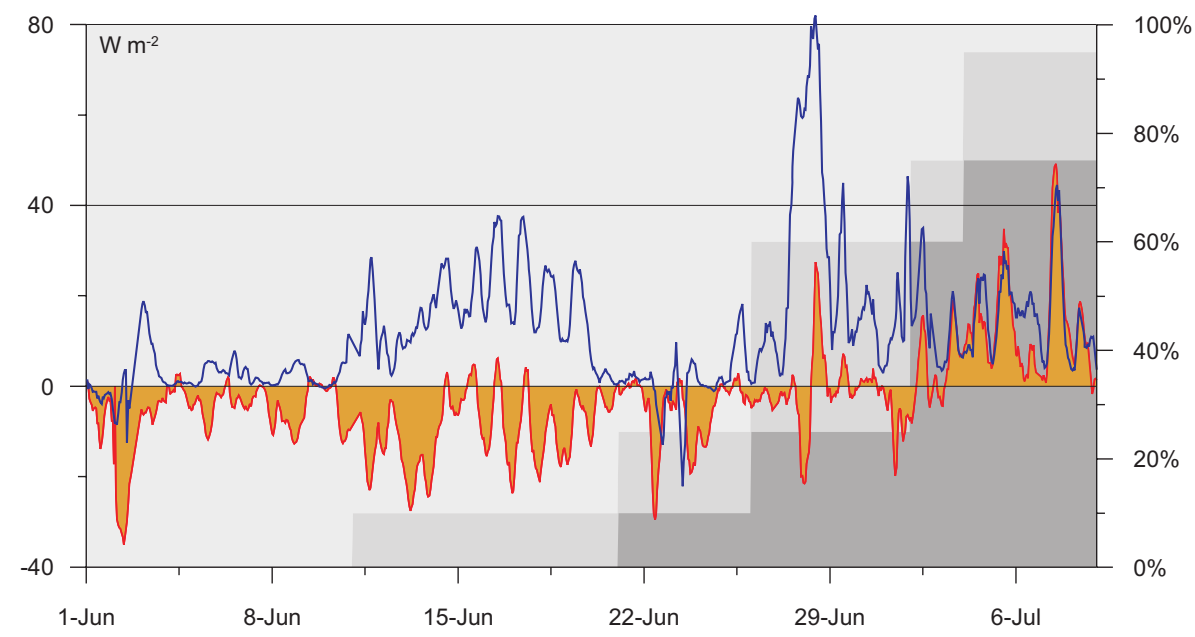

Fig. 13. Sensible (red) and latent heat flux (blue) for the snow melt and the beginning of the summer period (left axis). The light gray area represents the snow-covered and the dark gray area the snow-free fraction of the surface area around the eddy covariance system (right axis), which is taken to be approx. equal to the $90 \%$ source limit shown in Fig. 1c. The intermediate gray area indicates the uncertainty in area fraction between consecutive surveys.

snow. It is partly compensated by the net long-wave radiation $\Delta L$, so that the average net radiation $\Delta S+\Delta L$ is around $-40 \mathrm{Wm}^{-2}$. Until large snow-free patches appear, the air temperature is confined in a narrow range between $-1{ }^{\circ} \mathrm{C}$ and $+5^{\circ} \mathrm{C}$ and the snow surface temperature remains close to $0{ }^{\circ} \mathrm{C}$ due to the melt processes, so that the resulting temperature gradient is necessarily small. This yields weak sensible heat fluxes, with peak values around $-20 \mathrm{Wm}^{-2}$ and an average of $-6 \mathrm{Wm}^{-2}$. The positive latent heat flux, which causes a cooling of the surface, becomes more and more significant during the snow melt period, with an average of $11 \mathrm{Wm}^{-2}$. Most likely, it is stimulated by the presence of water due to the melting snow.

During the snow melt period, the net radiation $\Delta S+\Delta L$ is a much stronger energy supply channel compared to the sensible heat flux (Fig. 12, Table 2). The snow melt can therefore be considered as almost entirely controlled by radiation, which confirms earlier studies during snow melt by Harding and Lloyd (1998) and Boike et al. (2003a) at the same location. Our study can also confirm the order of magnitude and sign of the fluxes of these previous studies.

During snow melt, infiltrating melt water and subsequent refreezing processes dominate the snow pack, which is more or less isothermal close to $0^{\circ} \mathrm{C}$. The underlying soil still shows colder temperatures, which results in a heat transport from the snow-soil interface into the soil. The energy consumed by this ground heat flux is provided by the cooling and refreezing of melt water at the snow-soil interface, but initially originates from the short-wave radiation. At $13 \mathrm{Wm}^{-2}$ (estimated with the bulk method), this ground heat flux constitutes an important component of the surface energy budget. The large value can be explained by the fact that the temperatures in the upper soil column are within the freezing range of the soil (Roth and Boike, 2001), where a temperature change is associated with a change in latent heat content.

The sensible and latent heat fluxes during the snow melt period and the first eight days of the summer period, when snow patches were still present, are displayed in Fig. 13. As in winter, pronounced flux peaks such as the one around 15 June are associated with high wind speeds and neutral stratifications. Dewfall or white frost (negative latent heat flux), which has been found during snow melt in previous studies (Takeuchi et al., 1995; Boike et al., 2003b), occurs in few cases, but is insignificant as an energy source for snow melt. In 2008, the evolution of the snow-free areas around the eddy covariance system was monitored in intervals of two to ten days using aerial photography and systematic GPS-surveys. The results show that a patchwork of snow-covered and snow-free surfaces exists for several weeks due to the large spread in snow depth throughout the study area. Snow-free areas feature a completely different energy turnover compared to the snow patches. Accordingly, the sensible and latent heat fluxes must be seen as a mixture of both surface properties and their relevant percentages of the total footprint area. An example is the pronounced latent heat flux peak of about $80 \mathrm{Wm}^{-2}$ on 28 June (Fig. 13), which is presumably triggered by a high percentage of wet snowfree patches with strong evaporation in the footprint at that time. Meanwhile, the sensible heat flux is still negative or only slightly positive with absolute values below $20 \mathrm{Wm}^{-2}$, most likely because the remaining cold snow patches prevent a net exchange of sensible heat. The sensible heat flux keeps on alternating between negative and positive values for another couple of days, until it finally turns positive, after about three quarters of the area are free of snow (Fig. 13). 


\section{Discussion}

\subsection{Measurement errors and energy balance closure}

For nearly all periods, a residual term of the surface energy budget remains, which is usually found in investigations of the surface energy budget (overview in Foken, 2008a). We can identify four levels of uncertainty in our study: a) measurement errors; b) uncertainties due to assumptions taken or parameters used; c) inconsistencies due to different measurement locations and/or footprint areas; d) systematic bias inherent in the measurement method.

a) For turbulent flux measurements with a similar eddy covariance system, Mauder et al. (2006) estimate relative uncertainties between 5 and $15 \%$ for data of the quality classes 1 to 6 (Foken and Wichura, 1996) which we use in our study. The BSRN radiation measurements have an accuracy of better than $10 \mathrm{Wm}^{-2}$ (Ohmura et al., 1998). Unsupervised measurements under arctic conditions bear an additional potential for measurement errors due to e.g. snow-covered sensors or instrument malfunctions. The unmaintained radiation measurements are checked against the reference data set of the BSRN station, so that unreasonably large deviations are prevented. The soil temperature measurements from which the ground heat flux is inferred contain a few spikes and erroneous measurements, which are not considered in the evaluation. We conclude that random measurement errors and data gaps do not strongly influence the long-term averages presented in this study. Only in the fall period, data gaps of the turbulent fluxes occur frequently (see Sect. 4.2), so that a bias of the average fluxes is possible.

b) To evaluate the thermal conductivity, the soil and snow are idealized as a domain with constant thermal properties (in space and time) and purely conductive heat transfer is assumed (see Appendix A). In reality, the soil or snow properties can change, which is reflected in different values for the thermal diffusivity, if the fit is conducted for different periods (see Sect. 3.4). The range of obtained diffusivity values, in conjunction with the spread of soil or snow compositions determined in field measurements, is used to estimate the uncertainty of the thermal conductivity. Despite the resulting relative error of $25-30 \%$, the absolute error of the ground or snow heat flux remains at least a factor of four smaller than the energy balance closure term due to the generally low magnitude of the fluxes. Another issue associated with the ground heat flux is the storage effect of the thin soil layer above the uppermost sensor, which is not accounted for in the calculation of $Q_{g}$. However, the day and night-time contributions of this effect cancel, so it is insignificant on the considered timescales. c) Point measurements from different locations are considered as well as eddy covariance measurements, which integrate over an extended footprint area (Amiro, 1998; Schmid, 2002) with considerable small-scale heterogeneity of the surface cover (Fig. 1c). As the study focuses on average fluxes, only a sustained difference between the average flux of the eddy footprint area and the flux at the point measurement site is of importance. Firstly, this may be the case for the albedo, mainly for the snow melt, summer and fall period. From 40 point measurements (see Sect. 3.2), we estimate the spread in summer albedo throughout the study area and thus the albedo uncertainty to about 0.05 . For the snow melt period, the albedo value is estimated from the BSRN station, where the albedo decreases from 0.8 to 0.5 during the course of the snow melt. An additional uncertainty arises, as a small fraction of snow-free surfaces with much lower albedo contributes to the eddy footprint area at the end of the snow melt period (Fig. 13), so that a maximum albedo uncertainty of 0.1 appears realistic during snow melt. The potential bias in net short-wave radiation may thus be as large as $8 \mathrm{Wm}^{-2}$ for the summer and $25 \mathrm{Wm}^{-2}$ for the snow melt period, while it is presumably negligible for the other periods

In addition to albedo variations, the average surface temperature could vary due to differences in soil moisture and surface properties, which would affect both $L_{\text {out }}$ and $Q_{g}$. A sustained difference of $1 \mathrm{~K}$ would lead to a bias of $L_{\text {out }}$ on the order of $5 \mathrm{Wm}^{-2}$, so the spatial variability of surface temperatures deserves attention in future studies (Langer et al., 2009). An uncertainty in the ground heat flux is not only induced by variations of the surface temperature, but also by spatial variations of the soil properties, which most likely occur throughout the study area. However, the good agreement between the fluxes inferred with different methods from the locations P1 and P3 during the summer period gives us confidence in the accuracy of $Q_{g}$, within the liberal error estimates of about 25-30\% (see above).

d) A basal ice layer present in parts of the study area has not been included in the survey of snow water equivalent prior to snow melt (see Sect. 3.5). An average ice layer thickness of $5 \mathrm{~cm}$ corresponds to an additional flux of $5 \mathrm{Wm}^{-2}$, so the true value of $Q_{\text {melt }}$ during the snow melt period is most likely higher than $27 \mathrm{Wm}^{-2}$ (Table 2). Furthermore, there may be a contribution of $Q_{\text {melt }}$ in the pre-melt period (see Sect. 4.5).

Large eddy or secondary circulation patterns, advection and free convection events (Lüers and Bareiss, 2009a) are known to lead to a systematic underestimation of the true sensible and latent heat fluxes with the eddy covariance method (Inagaki et al., 1996). Flux losses exceeding 25\% have been estimated for both the sensible and latent heat flux (Foken, 2008a), which could explain a large part of 
the closure term in our study. At least in the summer and dark winter period where the closure terms are largest (we do not consider the pre-melt period as the contribution of snow melt is unclear), the signs of the dominant turbulent flux terms and the closure term match, so that the energy balance could indeed be closed by increasing the magnitude of the turbulent fluxes (Foken, 2008a). The wider area around the study site is dominated by mountains, glaciers and the open water body of the Kongsfjorden, so large temperature contrasts and extremely inhomogeneous surface heating exist over distances of a few kilometres, which most likely create advective circulation patterns. We cannot provide an independent estimate of the magnitude of the flux bias caused by these features, which could only be examined by area-averaging flux measurements, e.g. using scintillometers (Meijninger et al., 2006), or Large Eddy Simulation (LES) studies of the entire boundary layer dynamics (Beare et al., 2006).

We conclude that the magnitude of the observed closure terms is still in range of the closure terms found in a number of carefully designed field experiments (overview in Foken, 2008a), despite the measurement uncertainties under arctic conditions. Therefore, it seems reasonable that the true magnitude and relative importance of the terms of the surface energy budget do not differ substantially from the results given in this study.

\subsection{The annual energy budget}

The presented data set allows an estimate for the annual net budget for each of the components of the energy budget (see Table 2). With an average value of $-35 \mathrm{Wm}^{-2}$, the net shortwave radiation is the dominant source of energy. It is almost compensated by the net long-wave radiation, with an annual average of $32 \mathrm{Wm}^{-2}$. The latent heat flux is usually positive, and the annual average of $6.8 \mathrm{Wm}^{-2}$ is almost exclusively a result of strong fluxes during snow melt, summer and fall. The value corresponds to a water loss of approx. $85 \mathrm{~mm}$, so that about $20 \%$ of the precipitation of the study period evaporates or sublimates. While insignificant for the overall energy budget, positive average latent heat fluxes are detected during the polar night, which was not found at similar latitudes on arctic sea ice by the SHEBA study (Persson et al., 2002). The average sensible heat flux is negative with a value of $-6.9 \mathrm{Wm}^{-2}$, but shows a strong seasonal dependence. While the study site is actually a strong heat source for the atmosphere during the two months of summer $\left(Q_{h}=22.5 \mathrm{Wm}^{-2}\right)$, it is a heat sink for the rest of the year, with an average of $Q_{h}=-13 \mathrm{Wm}^{-2}$. During winter, the nearby ice-free sea is most likely an important heat source for the near-surface atmosphere, which might increase the air temperatures at the study site and thus fuel the relatively strong sensible heat transfer to the snow surface. The average ground heat flux is close to zero, as should be the case for equilibrium or near-equilibrium conditions of the permafrost. A strong warming of the permafrost at the study site has not occurred over the course of the considered year.

During winter, the system is entirely forced by long-wave radiation, while a strong short-wave forcing dominates the system during summer. The timing of the albedo change induced by the snow melt is a key point for the annual surface energy budget, since the snow at the study site usually disappears between end of May and beginning of July (Winther et al., 2002), when the incoming short-wave radiation reaches its annual maximum with daily averages of about $-200 \mathrm{Wm}^{-2}$. In contrast, the timing of the albedo change due to the formation of the snow cover in fall is of little importance, as the daily average for incoming shortwave radiation is already low during September, when the permanent snow cover usually forms (Winther et al., 2002).

Given the present data set, an earlier termination of the snow melt, e.g. by end of May instead of end of June, would not only lead to an increase of the net short-wave radiation in the annual budget, but also to an enhanced flux of latent heat. In case of the sensible heat flux, the ratio between summer conditions with atmospheric warming and winter conditions with atmospheric cooling would be shifted, resulting in a smaller, but presumably still negative net sensible heat flux.

\subsection{Implications for permafrost}

At the study site, the seasonal thaw of the active layer after snow melt is driven by short-wave radiation. About $15 \%$ of the total net radiation during the summer season is consumed by the ground heat flux, which compares well to the value found by Harding and Lloyd (1998). However, a pronounced warming of the soil towards $0{ }^{\circ} \mathrm{C}$ already occurs during snow melt. This leads to a significant increase in unfrozen water and thus latent heat content according to the freezing characteristics of the soil. The overall magnitude of the occurring heat flux in the ground is in good agreement with the findings of Boike et al. (2003b). The energy is mainly supplied by short-wave radiation, but is mediated through conduction in the snow pack or percolating and refreezing melt water. The increase in latent heat content of the soil during snow melt facilitates a more rapid thawing of the ground, after the snow has melted.

In September, when the incoming short-wave radiation is much lower than in the summer season, a further increase in active layer depth has been recorded in 2008. Hereby, the additional energy input by the sensible heat flux due to the influx of warm air masses most likely plays a significant role.

During winter, the most important factor for the permafrost is the incoming long-wave radiation, as it determines the general magnitude of the surface temperature (Fig. 7), which in turn finally governs the energy loss of the ground. Since the incoming long-wave radiation is mainly determined by synoptical weather patterns and thus air mass distribution and cloud properties (Yamanouchi and Ørbaek, 
1995), the permafrost is mainly susceptible to changes in these large-scale systems. For the on Svalbard anomalously warm winter of $2005 / 2006$, which was characterized by a sustained influx of relatively warm air masses, Isaksen et al. (2007) detected a thermal response of the permafrost to depths of $15 \mathrm{~m}$. The influx of warm southerly air masses can culminate in rain-on-snow events, which lead to a longlasting warming of the snow pack and thus the near-surface permafrost. Putkonen and Roe (2003) showed, that few strong rain-on-snow events can confine the temperature at the bottom of the snow to around $0^{\circ} \mathrm{C}$ for most of the winter.

During winter, the strong near-surface temperature inversion is a striking feature, which clearly limits the use of air temperatures as surrogate for the temperature of the snow surface (Lüers and Bareiss, 2009b). In the present study, the average temperature difference between the air temperature at $10 \mathrm{~m}$ height and the surface temperature was measured to be more than $3 \mathrm{~K}$ for the dark winter period. It should be carefully checked, whether this strong near-surface inversion is accounted for by models, which calculate the surface temperature based on a closed surface energy budget (e.g. Hinzman et al., 1995; Hoelzle et al., 2001).

\section{Summary and outlook}

In this study, we have documented the annual cycle of the surface energy budget at a high-arctic permafrost site for the example of the year 2008/2009:

1. During polar night conditions in winter, the long-wave radiation, the sensible heat flux and the heat input from the refreezing active layer have been identified as the main components of the surface energy budget. The incoming long-wave radiation is the determining factor for the surface temperature of the snow, but a significant influence particularly of the sensible heat flux remains.

2. During the snow-free period of the polar day season, the system is governed by the short-wave radiation, while turbulent fluxes and the long-wave radiation are the main balancing factors in the surface energy budget.

3. A more "winter-like" surface energy budget is found during the first half of the polar day season due to the the long-lasting snow cover with its high albedo, which effectively limits the role of the short-wave radiation. The albedo change induced by the snow melt is therefore of critical importance for the annual surface energy budget, as it marks the transition point between two fundamentally different regimes.

Due to its central role in the annual cycle, the correct representation of the snow melt must be considered crucial for both monitoring and modeling schemes in permafrost areas. During arctic winter and especially polar night conditions, the parameterization of the relevant processes of energy exchange between surface and atmosphere remains one of the major deficiencies in current models. A number of studies have suggested improved parameterizations for the sensible heat flux under stable conditions (e.g. Grachev et al., 2007), which have to be incorporated in existing process-based permafrost models, so that they can be successfully applied over a full seasonal cycle. Further studies will focus on the validation and improvement of such models by exploiting the hourly resolution of the current data set.

The study is performed at a site on Svalbard where a significant warming trend is expected in the near future, so it can be considered a baseline study to assess future shifts in the surface energy budget. It must be emphasized that an ongoing monitoring of radiation, land-atmosphere exchange processes and ground heat fluxes is indispensable to gain a better understanding of future changes and their impact on permafrost. This should include the winter season, where the most pronounced future warming is projected to occur (Førland and Hanssen-Bauer, 2003). Major improvements to the accuracy could be achieved by: 1) a detailed footprint analysis of the eddy covariance measurements in conjunction with spatially resolved measurements of the surface radiation and the ground heat flux; 2) area-averaging measurements of sensible and latent heat fluxes with large aperture and microwave scintillometers; and 3) the application of Large Eddy Simulations (LES) for a better understanding of the vertical structure of the arctic troposphere and the meso-scale large eddy or secondary circulation patterns in the wider Kongsfjorden area. Such studies may also allow to assess the impact of larger-scale factors, such as synoptic weather patterns, precipitation or sea ice conditions, on the surface energy budget of the study site.

In its exclusive use of measured rather than modeled values, the presented data set is unique for arctic land areas. Such comprehensive observations of soil, snow and atmospheric quantities, which could serve as a test data set to validate and support modeling efforts, are sparse for the Arctic. While Eugster et al. (2000) have compiled a data basis on the summer surface energy budget for a range of arctic tundra and boreal ecosystems, similar efforts covering the entire annual cycle have not yet been accomplished. Such a compilation would be of fundamental value in order to improve the understanding of physical processes involved in the surface energy budget and permafrost-snow-atmosphere interactions on arctic land areas.

\section{Appendix A}

\section{Calculation of ground heat fluxes}

To calculate the ground heat flux

$j_{z}(z, t)=-K_{h}(z, t) \frac{\partial}{\partial z} T(z, t)$ 
from temperature profile measurements, the first step is to evaluate the thermal conductivity $K_{h}$ of the soil or snow. For this purpose, we select three time series of temperature measurements in a profile, $T_{\text {meas }}\left(z_{1}, t\right), T_{\text {meas }}\left(\mathrm{z}_{2}, t\right)$ and $T_{\text {meas }}\left(z_{3}, t\right)$ with $z_{1}<z_{2}<z_{3}$. We then assume a conductive 1-D-heat transport without phase change of water according to Fourier's law

$\frac{\partial}{\partial t}\left(c_{h}(z, t) T(z, t)\right)+\frac{\partial}{\partial z} j_{z}(z, t)=0$

where $c_{h}$ denotes the heat capacity of the soil or snow, respectively. If heat capacity $c_{h}$ and thermal conductivity $\mathrm{K}_{h}$ are constant, Eq. (A2) simplifies to

$$
\frac{\partial}{\partial t} T(z, t)-d_{h} \frac{\partial^{2}}{\partial z^{2}} T(z, t)=0
$$

where $d_{h}=K_{h} / c_{h}$ denotes the thermal diffusivity of the soil or snow. To solve Eq. (A3) numerically, we assume Dirichlet boundary conditions given by the time series $T_{\text {meas }}\left(z_{1}, t\right)$ and $T_{\text {meas }}\left(z_{3}, t\right)$ of two outer temperature sensors in the profile. The initial condition is chosen as a linear interpolation between the first two data points of the boundary conditions. In this case, the exact choice of the initial condition is not critical, since the solution converges to a value independent of the initial condition after few time steps. The numerical solution of Eq. (A3) is performed with the partial differential equation solver of MATLAB, yielding the modeled times series of temperatures for a given $d_{h}, T_{d_{h}}\left(z_{2}, t\right)$, for all values of $z_{2}$ with $z_{1}<z_{2}<z_{3}$.

With $T_{\text {meas }}\left(z_{2}, t\right)$, we can perform a least-square fit for $d_{h}$ by minimizing the RMS error between $T_{\text {meas }}\left(z_{2}, t\right)$ and $T_{d_{h}}\left(z_{2}, t\right)$. Note that this method relies on rapid temperature changes which induce a time lag of the surface temperature signal in deeper soil layers characteristic for a certain $d_{h}$. In the summer period, when a strong diurnal temperature signal exists, the method generally works at the study site for depths of $z_{1} \approx 0.01 \mathrm{~m}, z_{2} \approx 0.15 \mathrm{~m}$ and $z_{3} \approx 0.30 \mathrm{~m}$ below the surface.

The same procedure is used by Putkonen (1998), and the basic idea of obtaining soil properties from a time series of temperature measurements is extended by Nicolsky et al. (2007) and Nicolsky et al. (2009).

When the heat capacity $c_{h}$ of the soil is estimated from soil samples, the thermal conductivity $\mathrm{K}_{h}$ can be evaluated. The heat flux $j_{z_{1}}(t)$ through the upper boundary can then be calculated using

$j_{z_{1}}=-\left.K\left(z_{1}, t\right) \frac{\partial}{\partial z} T(z, t)\right|_{z=z_{1}}$.

Note that the required derivative of the temperature can be easily evaluated since the numerical solution of Eq. (A3) delivers the full temperature field between $z_{1}$ and $z_{3}$.
Acknowledgements. We are grateful to M. Maturilli for providing us with the data of the BSRN station. We thank M. Schumacher, R. Vockenroth, E. Larmanou, M. Sieber and A. le Tressoler from the AWIPEV base in Ny-Ålesund for the ongoing support of our permafrost research, which contributed greatly to the success of this work. We are thankful to the Department of Micrometeorology of the University of Bayreuth headed by Foken for the advice and for the use of the eddy-covariance post-processing software. We thank two anonymous referees who gave valuable suggestions for improvement of the manuscript. We gratefully acknowledge financial support by the Helmholtz Association through a grant (VH-NG 203) awarded to Julia Boike.

Edited by: S. Gruber

\section{References}

Amiro, B.: Footprint climatologies for evapotranspiration in a boreal catchment, Agr. Forest Meteorol., 90, 195-201, 1998.

Beare, R., MacVean, M., Holtslag, A., Cuxart, J., Esau, I., Golaz, J., Jimenez, M., Khairoutdinov, M., Kosovic, B., Lewellen, D., et al:: An intercomparison of large-eddy simulations of the stable boundary layer, Bound.-Lay. Meteorol., 118, 247-272, 2006.

Beine, H., Argentini, S., Maurizi, A., Mastrantonio, G., and Viola, A.: The local wind field at Ny-Ålesund and the Zeppelin mountain at Svalbard, Meteorol. Atmos. Phys., 78, 107-113, 2001.

Boike, J., Hinzman, L., Overduin, P., Romanovsky, V., Ippisch, O., and Roth, K.: A comparison of snow melt at three circumpolar sites: Spitsbergen, Siberia, Alaska, in: Proceedings of the 8th International Conference on Permafrost, Zürich, Switzerland,2125, 2003a.

Boike, J., Roth, K., and Ippisch, O.: Seasonal snow cover on frozen ground: Energy balance calculations of a permafrost site near Ny-Ålesund, Spitsbergen, J. Geophys. Res.-Atmos., 108, 81638173, 2003b.

Boike, J., Ippisch, O., Overduin, P., Hagedorn, B., and Roth, K.: Water, heat and solute dynamics of a mud boil, Spitsbergen, Geomorphology, 95, 61-73, 2008.

Bussières, N.: Thermal features of the Mackenzie Basin from NOAA AVHRR observations for summer 1994, Atmos.-Ocean, 40, 233-244, 2002.

Campbell, G., Jungbauer Jr, J., Bidlake, W., and Hungerford, R.: Predicting the effect of temperature on soil thermal conductivity, Soil Sci., 158, 307-313, 1994.

Chapin, F., Eugster, W., McFadden, J., Lynch, A., and Walker, D.: Summer differences among arctic ecosystems in regional climate forcing, J. Climate, 13, 2002-2010, 2000.

Chapin, F., Sturm, M., Serreze, M., McFadden, J., Key, J., Lloyd, A., McGuire, A., Rupp, T., Lynch, A., Schimel, J., et al.: Role of land-surface changes in Arctic summer warming, Science, 310, 657-660, 2005.

Comiso, J. and Parkinson, C.: Satellite-observed changes in the Arctic, Physics Today, 57, 38-44, 2004.

Comiso, J., Parkinson, C., Gersten, R., and Stock, L.: Accelerated decline in the Arctic sea ice cover, Geophys. Res. Lett., 35, L01703, doi:10.1029/2007GL031972, 2008.

Cottier, F., Nilsen, F., Inall, M., Gerland, S., Tverberg, V., and Svendsen, H.: Wintertime warming of an Arctic shelf in response 
to large-scale atmospheric circulation, Geophys. Res. Lett., 34, L10607, doi:10.1029/2007GL029948, 2007.

De Vries, D.: The thermal conductivity of soil, Mededelingen van de Landbouwhogeschool te Wageningen, 52, 1-73, 1952.

Douville, H., Royer, J., and Mahfouf, J.: A new snow parameterization for the Meteo-France climate model, Clim. Dynam., 12, 21-35, 1995.

eklima: Free access to weather- and climate data from Norwegian Meteorological Institute from historical data to real time observations, online available at: http://www.eklima.no, 2009.

Eugster, W., Rouse, W., Pielke Sr, R., McFadden, J., Baldocchi, D., Kittel, T., Chapin, F., Liston, G., Vidale, P., Vaganov, E., and Chambers, S.: Land-atmosphere energy exchange in Arctic tundra and boreal forest: available data and feedbacks to climate, Glob. Change Biol., 6, 84-115, 2000.

Foken, T.: The energy balance closure problem - An overview, Ecol. Appl., 18, 1351-1367, 2008a.

Foken, T.: Micrometeorology, Springer, Berlin Heidelberg, Germany, 2008b.

Foken, T. and Wichura, B.: Tools for quality assessment of surfacebased flux measurements, Agr. Forest Meteorol., 78, 83-105, 1996.

Foken, T., Göckede, M., Mauder, M., Mahrt, L., Amiro, B., and Munger, J.: Post-field data quality control, in: Handbook of Micrometeorology: A guide for surface flux measurement and analysis, Kluwer, 2004.

Førland, E. and Hanssen-Bauer, I.: Past and future climate variations in the Norwegian Arctic: overview and novel analyses, Polar Res., 22, 113-124, 2003.

Førland, E., Hanssen-Bauer, I., and Nordli, P.: Climate statistics and longterm series of temperatures and precipitation at Svalbard and Jan Mayen, Det Norske Meteorologiske Institutt Klima Report 21/97, 1997.

Georgiadis, T., Bonafè, U., Calzolari, F., Nardino, M., Orsini, A., Pirazzini, R., Ravegnani, F., Sozzi, R., Trivellone, G., Argentini, S., et al.: Study of the surface energy balance at Ny-Ålesund, Svalbard, in: Conference Proceedings-Italian Physical Society, vol. 69, pp. 163-174, Editrice Compositori; 1999, 2000.

Gerland, S. and Renner, A.: Sea-ice mass-balance monitoring in an Arctic fjord, Ann. Glaciol., 46, 435-442, 2007.

Grachev, A., Andreas, E., Fairall, C., Guest, P., and Persson, P.: SHEBA flux-profile relationships in the stable atmospheric boundary layer, Bound.-Lay. Meteorol., 124, 315-333, 2007.

Hansen, J., Ruedy, R., Sato, M., Imhoff, M., Lawrence, W., Easterling, D., Peterson, T., and Karl, T.: A closer look at United States and global surface temperature change, J. Geophys. Res.-Atmos., 106, 23947-23963, 2001.

Hanssen-Bauer, I. and Førland, E.: Long-term trends in precipitation and temperature in the Norwegian Arctic: can they be explained by changes in atmospheric circulation patterns?, Climate Res., 10, 143-153, 1998.

Harding, R. and Lloyd, C.: Fluxes of water and energy from three high latitude tundra sites in Svalbard, Nordic Hydrol., 29, 267284, 1998.

Hinzman, L., Goering, D., and Kane, D.: A distributed thermal model for calculating soil temperature profiles and depth of thaw in permafrost regions, J. Geophys. Res.-Atmos., 103, 2897528991, 1995.

Hoelzle, M., Mittaz, C., Etzelmueller, B., and Haeberli, W.: Sur- face energy fluxes and distribution models of permafrost in European mountain areas: an overview of current developments, Permafrost and Periglacial Processes, 12, 53-68, 2001.

Inagaki, A., Letzel, M., Raasch, S., and Kanda, M.: Impact of surface heterogeneity on energy balance: A study using LES, J. Meteorol. Soc. Jpn, 84, 187-198, 1996.

Isaksen, K., Holmlund, P., Sollid, J., and Harris, C.: Three deep alpine-permafrost boreholes in Svalbard and Scandinavia, Permafrost and Periglacial Processes, 12, 13-25, 2001.

Isaksen, K., Sollid, J., Holmlund, P., and Harris, C.: Recent warming of mountain permafrost in Svalbard and Scandinavia, J. Geophys. Rese.-Earth Surf., 112, F02S04, doi:10.1029/ 2006JF000522, 2007.

Langer, M., Westermann, S., and Boike, J.: Spatial and temporal variations of summer surface temperatures of wet polygonal tundra in Siberia - implications for MODIS LST based permafrost monitoring, Remote Sens. Environ., submitted, 2009.

Ling, F. and Zhang, T.: A numerical model for surface energy balance and thermal regime of the active layer and permafrost containing unfrozen water, Cold Reg. Sci. Technol., 38, 1-15, 2004.

Lloyd, C., Harding, R., Friborg, T., and Aurela, M.: Surface fluxes of heat and water vapour from sites in the European Arctic, Theor. Appl. Climatol., 70, 19-33, 2001.

Lüers, J. and Bareiss, J.: Direct near surface measurements of sensible heat fluxes in the arctic tundra applying eddy-covariance and laser scintillometry - The Arctic Turbulence Experiment 2006 on Svalbard (ARCTEX-2006), Theor. Appl. Climatol., submitted, 2009a.

Lüers, J. and Bareiss, J.: The effect of misleading surface temperature estimations on the sensible heat fluxes at a high Arctic sitethe Arctic turbulence experiment 2006 on Svalbard (ARCTEX2006), Atmos. Chem. Phys. Discuss., 9, 16913-16939, $2009 \mathrm{~b}$.

Lynch, A., Chapin, F., Hinzman, L., Wu, W., Lilly, E., Vourlitis, G., and Kim, E.: Surface energy balance on the arctic tundra: Measurements and models, J. Climate, 12, 2585-2606, 1999.

Mauder, M. and Foken, T.: Documentation and instruction manual of the eddy covariance software package TK2, Univ. of Bayreuth, Dept. of Mikrometeorology, 2004.

Mauder, M., Liebthal, C., Göckede, M., Leps, J., Beyrich, F., and Foken, T.: Processing and quality control of flux data during LITFASS-2003, Bound.-Lay. Meteorol., 123, 67-88, 2006.

Mauder, M., Foken, T., Clement, R., Elbers, J. A., Eugster, W., Grünwald, T., Heusinkveld, B., and Kolle, O.: Quality control of CarboEurope flux data - Part 2: Inter-comparison of eddycovariance software, Biogeosciences, 5, 451-462, 2008, http://www.biogeosciences.net/5/451/2008/.

McFadden, J., Chapin, F., and Hollinger, D.: Subgrid-scale variability in the surface energy balance of arctic tundra, J. Geophys. Res.-Atmos., 103, 28947-28961, 1998.

McFadden, J., Eugster, W., and Chapin, F.: A regional study of the controls on water vapor and $\mathrm{CO}_{2}$ exchange in arctic tundra, Ecology, 84, 2762-2776, 2003.

Meijninger, W. M. L., Lüdi, A., Beyrich, F., Kohsiek, W., and DeBruin, H. A. R.: Scintillometer-based turbulent surface fluxes of sensible and latent heat over a heterogeneous land surface: a contribution to LITFASS-2003, Bound.-Lay. Meteorol., 121, 89110, 2006.

Moore, C.: Frequency response corrections for eddy correlation systems, Bound.-Lay. Meteorol., 37, 17-35, 1986. 
Nakabayashi, H., Kodama, Y., Takeuchi, Y., Ozeki, T., and Ishikawa, N.: Characteristics of heat balance during the snowmelt season in Ny-Ålesund, Spitsbergen Island, Memoirs of National Institute of Polar Research, Special issue, 51, 255-266, 1996.

Nicolsky, D. J., Romanovsky, V. E., and Tipenko, G. S.: Using insitu temperature measurements to estimate saturated soil thermal properties by solving a sequence of optimization problems, The Cryosphere, 1, 41-58, 2007,

http://www.the-cryosphere-discuss.net/1/41/2007/.

Nicolsky, D., Romanovsky, V., and Panteleev, G.: Estimation of soil thermal properties using in-situ temperature measurements in the active layer and permafrost, Cold Reg. Sci. Technol., 55, 120-129, 2009.

Oechel, W., Vourlitis, G., Brooks, S., Crawford, T., and Dumas, E.: Intercomparison among chamber, tower, and aircraft net $\mathrm{CO}_{2}$ and energy fluxes measured during the Arctic System Science Land-Atmosphere-Ice Interactions (ARCSS-LAII) Flux Study, J. Geophys. Res.-Atmos., 103, 28993-29003, 1998.

Ohmura, A., Gilgen, H., Hegner, H., Müller, G., Wild, M., Dutton, E., Forgan, B., Fröhlich, C., Philipona, R., Heimo, A., et al.: Baseline Surface Radiation Network (BSRN/WCRP): New precision radiometry for climate research, B. Am. Meteorol. Soc., 79, 2115-2136, 1998.

Overland, J., Wang, M., and Salo, S.: The recent Arctic warm period, Tellus A, 60, 589-597, 2008.

Persson, P., Fairall, C., Andreas, E., Guest, P., and Perovich, D.: Measurements near the Atmospheric Surface Flux Group tower at SHEBA: Near-surface conditions and surface energy budget, J. Geophys. Res.-Oceans, 107, 8045, doi:10.1029/2000JC000705, 2002.

Putkonen, J.: Soil thermal properties and heat transfer processes near Ny-Ålesund, northwestern Spitsbergen, Svalbard, Polar Res., 17, 165-179, 1998.

Putkonen, J. and Roe, G.: Rain-on-snow events impact soil temperatures and affect ungulate survival, Geophys. Res. Lett., 30, 1188, doi:10.1029/2002GL016326, 2003.

Rees, W.: Infrared emissivities of arctic land cover types, Int. J. Remote Sens., 14, 1013-1017, 1993.

Romanovsky, V. and Osterkamp, T.: Thawing of the active layer on the coastal plain of the Alaskan Arctic, Permafrost and Periglacial Processes, 8, 1-22, 1997.

Roth, K. and Boike, J.: Quantifying the thermal dynamics of a permafrost site near Ny-Ålesund, Svalbard, Water Resour. Res., 37, 2901-2914, 2001.
Schmid, H.: Source areas for scalars and scalar fluxes, Bound.-Lay. Meteorol., 67, 293-318, 1994.

Schmid, H.: Footprint modeling for vegetation atmosphere exchange studies: A review and perspective, Agr. Forest Meteorol., 113, 159-183, 2002.

Serreze, M., Walsh, J., Chapin, F., Osterkamp, T., Dyurgerov, M., Romanovsky, V., Oechel, W., Morison, J., Zhang, T., and Barry, R.: Observational evidence of recent change in the northern highlatitude environment, Climatic Change, 46, 159-207, 2000.

Slater, A., Pitman, A., and Desborough, C.: The validation of a snow parameterization designed for use in general circulation models, Int. J. Climatol., 18, 595-617, 1998.

Stöckli, R., Lawrence, D., Niu, G., Oleson, K., Thornton, P., Yang, Z., Bonan, G., Denning, A., and Running, S.: Use of FLUXNET in the Community Land Model development, J. Geophys. Res.-Biogeosciences, 113, G01025, doi:10.1029/ 2007JG000562, 2008.

Takeuchi, Y., Kodoma, Y., and Nakabayashi, H.: Characteristics of evaporation from snow and tundra surface in Spitsbergen in the snowmelt season 1993, in: Proceedings of the NIPR Symposium on Polar Meteorology and Glaciology, vol. 9, 54-65, 1995.

Uttal, T., Curry, J., Mcphee, M., Perovich, D., Moritz, R., Maslanik, J., Guest, P., Stern, H., Moore, J., Turenne, R., et al.: Surface heat budget of the Arctic Ocean, B. Am. Meteorol. Soc., 83, 255-275, 2002.

Viterbo, P. and Beljaars, A.: An improved land surface parameterization scheme in the ECMWF model and its validation, J. Climate, 8, 2716-2748, 1995.

Vourlitis, G. and Oechel, W.: Eddy covariance measurements of $\mathrm{CO}_{2}$ and energy fluxes of an Alaskan tussock tundra ecosystem, Ecology, 80, 686-701, 1999.

Winther, J., Godtliebsen, F., Gerland, S., and Isachsen, P.: Surface albedo in Ny-Ålesund, Svalbard: variability and trends during 1981-1997, Global Planet. Change, 32, 127-139, 2002.

Yamanouchi, T. and Ørbaek, J.: Comparative study of the surface radiation budget at $\mathrm{Ny}$-Ålesund, Svalbard and Syowa Station, Antarctica, 1987, in: Proceedings of the NIPR Symposium on Polar Meteorolgy and Glacialogy, National Institute of Polar Research, Japan, 118-132, 1995.

Zilitinkevich, S., Perov, V., and King, J.: Near-surface turbulent fluxes in stable stratification: Calculation techniques for use in general-circulation models, Q. J. Roy. Meteorol. Soc., 128, 1571-1587, 2002. 